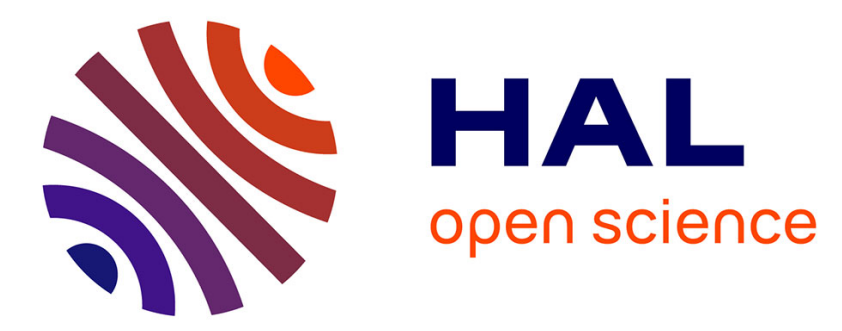

\title{
Anxiety, depression, and life satisfaction in parents caring for children with cystic fibrosis
}

Tanja Besier, Anja Born, Gerhard Henrich, Andreas Hinz, Alexandra

Quittner, Lutz Goldbeck

\section{- To cite this version:}

Tanja Besier, Anja Born, Gerhard Henrich, Andreas Hinz, Alexandra Quittner, et al.. Anxiety, depression, and life satisfaction in parents caring for children with cystic fibrosis. Pediatric Pulmonology, 2011, 46 (7), pp.672. 10.1002/ppul.21423 . hal-00619929

\section{HAL Id: hal-00619929 \\ https://hal.science/hal-00619929}

Submitted on 7 Sep 2011

HAL is a multi-disciplinary open access archive for the deposit and dissemination of scientific research documents, whether they are published or not. The documents may come from teaching and research institutions in France or abroad, or from public or private research centers.
L'archive ouverte pluridisciplinaire HAL, est destinée au dépôt et à la diffusion de documents scientifiques de niveau recherche, publiés ou non, émanant des établissements d'enseignement et de recherche français ou étrangers, des laboratoires publics ou privés. 


\section{Anxiety, depression, and life satisfaction in parents caring for children with cystic fibrosis}

\begin{tabular}{|r|l|}
\hline Journal: & Pediatric Pulmonology \\
\hline Manuscript ID: & PPUL-10-0293.R2 \\
\hline Diley - Manuscript type: & Original Article \\
\hline Author: & 27-Dec-2010 \\
\hline & $\begin{array}{l}\text { Complete List of Authors: } \\
\text { Medical Psychology and Medical Sociology } \\
\text { Henrich, Gerhard; University Hospital of the Technical University } \\
\text { Munich, Department of Psychosomatic Medicine } \\
\text { Hinz, Andreas; University of Leipzig, Independent Department for } \\
\text { Medical Psychology and Medical Sociology } \\
\text { Quittner, Alexandra; University of Miami, Psychology and Pediatrics } \\
\text { Goldbeck, Lutz; University Hospital Ulm, Child and Adolescent } \\
\text { Psychiatry/Psychotherapy }\end{array}$ \\
\hline Keywords: & $\begin{array}{l}\text { anxiety, cystic fibrosis, depression, life satisfaction, parent } \\
\text { caregivers }\end{array}$ \\
\hline
\end{tabular}

\section{SCHOLARONE ${ }^{\text {M }}$ Manuscripts}


Revised Manuscript draft for Pediatric Pulmonology - December 2010

Anxiety, depression, and life satisfaction in parents caring for children with cystic fibrosis

Tanja Besier, $\mathrm{PhD}^{1}$, Anja Born, M.Sc${ }^{2}$, Gerhard Henrich, $\mathrm{PhD}^{3}$, Andreas Hinz, $\mathrm{PhD}^{2}$, Alexandra L. Quittner, $\mathrm{PhD}^{4}$, Lutz Goldbeck, $\mathrm{PhD}^{1}$, and the TIDES study group

${ }^{1}$ University Hospital Ulm, Department of Child and Adolescent Psychiatry/Psychotherapy,

${ }^{2}$ University of Leipzig, Independent Department for Medical Psychology and Medical Sociology, ${ }^{3}$ University Hospital of the Technical University Munich, Department of Psychosomatic Medicine, ${ }^{4}$ University of Miami, Department of Psychology

All correspondence concerning this article should be addressed to Tanja Besier, $\mathrm{PhD}$,

University Hospital Ulm, Department of Child and Adolescent Psychiatry/Psychotherapy, Steinhoevelstr. 5, 89075 Ulm, Germany. Email: tanja.besier@uniklinik-ulm.de

Running head: Psychopathology in parents of minors with $\mathrm{CF}$ 


\begin{abstract}
Objective To assess the prevalence of symptoms of anxiety and depression and the extent of life satisfaction in parents caring for children with cystic fibrosis (CF) in Germany.

Methods The study included 650 caregivers of 564 children with CF ages 0 to 17 , who completed the Hospital Anxiety Depression Scale (HADS), the Center for Epidemiologic Studies Depression Scale (CES-D) and the Questions on Life Satisfaction (FLZ $\left.{ }^{\mathrm{M}}\right)$.

Results More than one-third (37.2\%) of parents showed elevated levels of anxious symptoms, compared to $18.9 \%$ of a population sample $(p \leq .001)$ and significantly more parents reported elevated levels of depressive symptoms compared to a community sample (28\% vs. $21 \%$, $p=.01)$. Higher levels of anxious and depressive symptoms were associated with lower life satisfaction $(p<.001)$.
\end{abstract}

Conclusions High levels of anxious and depressive symptoms among parents of children with $\mathrm{CF}$ suggested that annual symptom screening is warranted. This will facilitate identification of those at risk and provide referrals and intervention for those who are in need of it.

Keywords: Anxiety; cystic fibrosis; depression; life satisfaction; parent caregivers. 


\section{Introduction}

Chronic medical conditions, such as cystic fibrosis (CF), have significant implications for the psychosocial well-being of the family system. ${ }^{1}$ Parents of children with chronic illnesses must cope with uncertainty about progression of the disease, as well as challenges in everyday life, including adherence to complex treatment regimens, regular clinic visits, hospitalizations, financial stress due to costs of care, and disruptions in future plans. ${ }^{2}$ As a consequence of these caregiving challenges, parents are at a high risk for the development of psychological symptoms and decreased quality of life. ${ }^{3}$

Advances in medical care and treatments over the past 20 years have led to an increase in life span of patients with $\mathrm{CF}$, with a majority of children in developed countries now living into adulthood. ${ }^{4}$ However, management of CF requires adherence to a complex and timeconsuming treatment regimen, including inhaled and oral medications, airway clearance, and alterations in diet. ${ }^{5}$ In general, poor adherence (50\% or less) is reported in chronically ill pediatric populations ${ }^{6}$, and this was also shown for children with $\mathrm{CF}^{7}$. Adherence rates in children with CF vary depending on the specific treatment component, with adherence for chest physical therapy rated between $40-47 \%^{8}$ and approximately $51 \%$ in a newer US study ${ }^{7}$ and estimates being especially low for dietary recommendations ${ }^{9}$. Non-adherence can have serious consequences for the child's health status. Therefore, depending on the child's development, parents must take responsibility for administering and supervising the specific $\mathrm{CF}$ treatments, which has been shown to increase role strain in parents and lead to greater conflict with adolescents. ${ }^{3,10}$ Studies have demonstrated that parents' symptoms of depression and anxiety, as well as general family functioning show a strong association with health outcomes in patients with CF. ${ }^{11,12}$ These findings suggest that the impact of CF on parent caregivers' psychological functioning and quality of life requires further study. 
From the late 1960s on, studies have examined the impact of CF on parents/caregivers (for review see ${ }^{13,14}$ ) with most studies finding high levels of psychological distress and increased risk of depressive symptoms. ${ }^{15}$ A Turkish study on sleep quality and the psychological well-being of mothers caring for children with asthma or CF reported higher anxiety and depression scores than mothers of healthy children. ${ }^{16}$ A single center study in the US examining the relations between symptoms of psychological distress and quality of life in caregivers of children with $\mathrm{CF}^{17}$ found elevated rates of depressive and anxious symptoms, which were negatively correlated with parental quality of life. Rates of anxious symptoms were more pronounced (43-51\%) compared to $14-31 \%$ (depending of the measure used) of the parents reporting elevated levels of depressive symptoms. In another US study, over onethird of parents scored in the elevated range on a depression measure and more symptoms of depression were associated with worse adherence to enzymes as well as either loss of weight or failure to make expected weight gains in children with CF three months later ${ }^{18}$. Similarly, a single center study from Smith and colleagues found $35 \%$ of mothers and $23 \%$ of fathers reported elevated symptoms of depression and $57 \%$ of mothers and $25 \%$ of fathers reported elevated anxiety. Further, symptoms of depression in parents of school-age children were associated with worse adherence to airway clearance. ${ }^{19}$

Research has also shown that caring for a child with a chronic condition can negatively affect parents' quality of life, ${ }^{20,21}$ as they are confronted with the threat of a lifelimiting illness and additionally have to face multiple social and emotional stressors associated with their child's disease, e.g., fear, less time for social activities, financial burdens, etc. Also, parents` health-related quality of life proved to be worse than that reported by parents of healthy children. ${ }^{22,23}$ However, specific studies on the health-related quality of life of parents caring for a child with CF are rare. In the single-center study by Driscoll and colleagues already mentioned above, a good child lung functioning was 
associated with better quality of life in mothers caring for a child with CF. Depressive and anxious symptoms predicted parental quality of life, even after controlling for psychosocial treatment received by the caregiver. However, the relation was stronger between depressive symptoms and quality of life ${ }^{17}$.

To date, no large scale epidemiological studies have systematically examined the prevalence of anxiety and depression and subjectively reported quality of life of parents caring for a child with CF. Therefore "The International Depression/Anxiety Epidemiological Study" (TIDES, www.tides-cf.org) was initiated in 2007 with more than ten countries worldwide participating so far. The objectives were to screen for depressive and anxious symptoms in adolescent and adult patients with CF and parents caring for a minor child with $\mathrm{CF}$, and to link these psychological data to the patients` health outcomes. Here, parent data from the German arm of the study including $32 \mathrm{CF}$ Centers are presented. The patient data have been published elsewhere. ${ }^{24}$ Standardized screening tools were used to estimate the prevalence of anxious and depressive symptoms in parents caring for a child with CF. Further, rather than evaluating the broader concept of quality of life, the focus was on assessment of life satisfaction, defined as subjectively perceived quality of life based on individual preferences and reported satisfaction in multiple life domains. ${ }^{25}$

Thus, the purpose of the current study was to test the following hypotheses using a large, nationally representative sample:

1. Compared to the general population, symptoms of anxiety and depression were expected to be more prevalent in parent caregivers of minors (under age 18 years) with CF.

2. Life satisfaction was expected to be lower in parent caregivers of minors with $\mathrm{CF}$ than in the general population. 
3. Among parents, a significant negative association was expected between symptoms of anxiety/depression and life satisfaction.

\section{Materials and Methods}

\section{Procedure}

Data collection took place between February 2007 and April 2008. The study protocol was approved by the Institutional Review Board of the University of Ulm and the local IRBs at the 32 participating CF clinics (representing about one third of the German CF outpatient units). This study was part of a larger international prevalence study initiated in the United States (see www.tides-cf.org). During routine clinic visits, parents of children with CF ages 0 to through 17 were informed of the study's purpose and objectives and were asked to participate. After completion of informed consent, a demographics questionnaire and screening instruments (see below) for symptoms of anxiety/depression and life satisfaction were administered by a member of the CF team, such as a social worker, psychologist, or nurse. Anxious and depressive symptoms in parents were measured with the Hospital Anxiety and Depression Scale (HADS). Additionally, to measure parental depressive symptoms, the CES-D was administered, as the HADS Depression scale excludes relevant somatic items (e.g., fatigue). Thus, the CES-D was considered the primary measure and more appropriate screener for depressive symptoms. The Questions on Life Satisfaction $\left(\mathrm{FLZ}^{\mathrm{M}}\right)$ were used to evaluate parental life satisfaction. Completion of the questionnaires took about 20 minutes. The measures were scored immediately upon completion and if the participant scored above the clinical cut-off score ( $\geq 8$ points) on either the anxiety or depression scale, a referral to a mental health professional was initiated.

Parents also agreed to the collection of medical data on their child with CF, which were extracted from the German CF registry. The variables extracted were current height, 
weight, FEV1 in liters, FEV1\% predicted, colonization with germs (Pseudomonas aeruginosa yes/no; Burkholderia cepacia yes/no), complications during the last year (hemoptysis yes/no, pneumothorax yes/no or new diagnosis of CF-related Diabetes yes/no).

\section{Measures}

\section{$\underline{\text { Hospital Anxiety and Depression Scale (HADS) }}$}

The $\mathrm{HADS}^{26}$ is a brief and easy to administer 14-item instrument which measures symptoms of anxiety (7 items) and depression ( 7 items). It was designed specifically for use with chronically ill patients and therefore, physical symptoms (such as headaches or fatigue) that could be associated with a medical condition were excluded. The instrument has been translated into numerous languages and has been used extensively in different countries with different populations. Respondents rate each symptom using a 4-point scale (range 0-3), indicating the current extent of the symptom. Results of this screening measure can be analysed both categorically, discriminating normal (0-7 points), borderline (8-10 points) and clinical levels of symptoms ( $\geq 11$ points) as indicated by cut-off scores provided by the authors, and dimensionally by adding the raw scores of each scale.

The HADS has extensive reliability and validity data ${ }^{27,28}$ with strong internal consistency as measured by Cronbach's $\alpha$ of .82 for the Anxiety subscale (HADS-A) and .83 for the Depression subscale (HADS-D) in the current sample. Optimal sensitivity and specificity (approximately .80 each) was achieved most frequently using a cut-off score of 8 for the Anxiety scale. ${ }^{28}$ External validity has been demonstrated, with strong convergence found between the HADS and other validated anxiety and depression measures. In this study, the German version of the HADS ${ }^{29}$ was administered.

$\underline{\text { Center of Epidemiologic Studies Depression Scale (CES-D) }}$

The Center for Epidemiologic Studies Depression Scale, CES-D ${ }^{30}$ is a frequently used 20item self-report instrument screening for the major components of depression, including 
depressive mood, feelings of guilt and worthlessness, loss of appetite, and sleep disturbance. It was designed to assess all major symptoms of depression in community samples and has excellent psychometric properties, evidencing good internal consistency (Cronbach's $\alpha=.89$ in the current sample). For each item, respondents rate the frequency of their symptoms over the past week on a 4-point scale ranging from 0-3. All items scores are summed to yield a total score, ranging from 0-60. Higher scores indicate more depressive symptoms, with a score of 16 or higher identified as the clinical cut-off score for depressive symptoms. ${ }^{30}$ In this study, the German version of the CES-D ${ }^{31}$ was administered. In the German manual the use of an adapted cut-off score of 24 or higher is suggested, referring to a large but non representative community sample. To allow for international comparability, both, the international cut-off score of 16 and the German cut-off score of 24 were applied in this study.

\section{Questions on Life Satisfaction $\left(\mathrm{FLZ}^{\mathrm{M}}\right)$}

The Questions on Life Satisfaction (German: Fragen zur LebensZufriedenheit, FLZ ${ }^{\mathrm{M} 25}$ ) is a multidimensional measure of General and Health-related Life Satisfaction in eight domains of daily life (e.g., leisure time/hobbies, family life, physical condition, ability to relax, etc.). The instrument includes ratings of the subjective importance for each domain, which can be used to weight ratings of satisfaction. Each domain is evaluated twice, once for the importance and once for satisfaction, on 5-point rating scales ranging from 1 (not important/dissatisfied) to 5 (extremely important/very satisfied). Weighted scores for each item are then calculated using the following formula: weighted satisfaction $=($ importance rating -1$) x((2 x$ satisfaction rating)-5). ${ }^{25}$ Item-specific weighted scores range from -12 to +20 , with negative scores indicating dissatisfaction with the domain measured. Domains without subjective importance are weighted 0 , and thus do not impact the individual's life satisfaction. Total scores for General and Health-related Life Satisfaction are computed by summing the eight general and 
eight health-related domain scores, and they range from -96 to +160 . Higher scores indicate better satisfaction with life. Good reliability and validity of the $\mathrm{FLZ}^{\mathrm{M}}$ has been reported in previous studies using the instrument with adolescent and adult populations. ${ }^{25,32-34}$ In the current sample Cronbach's $\alpha$ was .83 for the General Life Satisfaction module and .88 for the Health-related Life Satisfaction module.

\section{Statistical analyses}

To allow for group comparisons, we used the most recent instrument-specific data from normative reference samples. For the HADS data, we used data from a German survey study. ${ }^{35}$ The general population sample was selected based on 216 sample points in Germany using the random-route-technique (random selection of street, house, flat and target subject in the household). This sample, with a response rate of $68 \%$, can be assumed to be representative of the adult German population living in private households. Individuals from foreign countries were not included in the sample because of problems with command of the German language. The original sample, with complete data consisted of 2037 people aged 14-92 years, with a mean age of $49.2(\mathrm{SD}=17.3)$. These respondents were matched for age and gender with our parent sample, leading to a sample size of 614 (22-60 years, $M=40.0$ years, $S D=7.2$, $76.4 \%$ female).

To analyse the CES-D data we used comparative data from a representative population sample in cooperation with the German study group mentioned above $(N=2005,14-91$ years, $M=48.0, S D=18.3)$. Matching for age and gender led to a sample size of 620 people aged 2160 years $(M=40.0$ years, $S D=7.3,76.6 \%$ female $)$.

The life satisfaction data, measured with the Questions on Life Satisfaction (FLZ ${ }^{\mathrm{M}}$ ), were also compared to community samples. For the general life satisfaction module, data came from a large community sample $(N=5036,14-92$ years, $M=48.4, S D=18.0,53.7 \%$ female). Comparison data for the health-related life satisfaction module came from the FLZ ${ }^{\mathrm{M}}$ 
standardization study ${ }^{36}$ with 1338 German adults from the community (17-95 years, $M=46.9$, $S D=17.2,54.6 \%$ female). An analogous matching procedure was completed for both samples, selecting those participants with an age-gender combination paralleling the parent caregiver sample. Their responses were weighted so that the age and gender distribution in the two community samples paralleled the distribution in the parent caregiver sample. The matching procedure resulted in a sample of 2718 subjects for the general life satisfaction module and 768 subjects for the health-related life satisfaction module.

The frequencies of elevated HADS Anxiety and Depression scores and CES-D scores were calculated using the established cut-off scores. Group comparisons with the community sample, matched for age and gender, were performed using $\chi^{2}$-tests. Gender differences comparing the mean scores of mothers and fathers were determined using Student's $t$-tests. Associations of elevated levels of anxious/depressive symptoms and the following sociodemographic and disease-related variables were determined applying Chi square tests or $t$ tests for independent samples: parent education $(0=10$ years of school or less, $1=$ "Abitur" or university degree), parent employment ( $0=$ no employment outside of the home, 1=employment outside of the home), parent age, child age, and FEV1\% as indicator for child health status. FLZ ${ }^{\mathrm{M}}$ raw scores were transformed into weighted scores and two total scores were calculated for General and Health-related Life Satisfaction. Student's $t$-tests for independent samples were used to examine potential differences between the parent and matched community sample. Spearman's rho was used to test the associations between life satisfaction and the same sociodemographic and disease-related variables that were used to explore the associations with parental anxious and/or depressive symptoms. To test the associations among symptoms of anxiety and depression and life satisfaction, univariate analyses of covariance (ANCOVAs) were calculated with the level of anxious symptoms (normal - borderline - abnormal) and depressive symptoms as measured with the CES-D 


\section{Results}

\section{Sample Characteristics}

A total of 650 parent caregivers of 564 minors with $\mathrm{CF}(0-17$ years, $M=9.5, S D=4.6$; $54.9 \%$ male) were consecutively recruited for the study during a routine clinic visit at their $\mathrm{CF}$ center. This was approximately $50 \%$ of all eligible families at the participating sites. Reasons for non-participation included no time, no interest in the study, data protection concerns, etc. In 478 cases, data were obtained from only one parent ( 73 fathers, 405 mothers), whereas we received two data sets (one from father, one from mother) for the remaining 86 children. Children's lung function, measured as $\mathrm{FEV}_{1} \%$ predicted, ranged from $15.7 \%$ to $138.7 \%$ $(\mathrm{M}=89.8 \%, \mathrm{SD}=21.1)$, with $83.2 \%$ of the children falling in the normal to mild range of disease severity $\left(\mathrm{FEV}_{1} \% \geq 70\right)$ and only $2.5 \%$ falling in the severely impaired range $\left(\mathrm{FEV}_{1} \%\right.$ <40). In 17 cases $(3.1 \%)$ the patients were experiencing acute medical conditions. The parents of these patients were included in the study sample; however, comparisons were made to the rest of the parents whose children were currently not sick or experiencing pulmonary exacerbations. Table 1 shows the characteristics of the parent sample, separately for mothers and fathers. 
Participating patients were compared to those not participating in this study, but whose data are included in the German CF Registry. These data included socio-demographic (e.g., age, gender, education, living situation) and medical information (e.g., height, weight, $\left.\mathrm{FEV}_{1} \%\right)$. Fewer parents with children under the age of 6 years $(\mathrm{p}<.001)$ participated in this study than were represented in the Registry, and thus there were a few differences on agecorrelated indicators (lower height and weight in the study sample, as expected for this age group). No other group differences were found, indicating that this sample was representative of the school-age and adolescent CF cohort in Germany.

\section{$\underline{\text { Symptoms of anxiety and depression }}$}

Parents of children with CF reported significantly more symptoms of anxiety than the general population (see figure 1). At least borderline elevations in anxious symptoms were reported by $37.2 \%$ of parent caregivers, with $17.0 \%$ in the clinical range. In contrast, only $18.9 \%$ of the general population reported borderline symptoms and $5.2 \%$ reported symptoms in the clinical range $\left(\chi^{2}=59.208, p<.001\right)$. Among parents, the most frequently reported items on the Anxiety scale were "I feel restless as I have to be on the move" (M=1.16, SD=1.0), "I get a sort of frightened feeling as if something awful is about to happen" $(M=1.16, S D=0.9)$, and "I feel tense or wound up" $(M=1.15, S D=0.8)$. In general, mothers of children with CF reported significantly more anxious symptoms than fathers (mothers: $M=6.7, S D=3.9$ versus fathers: $M=5.9, S D=3.7, t=-2.29, p=.02)$. There were no significant differences in anxious symptoms regarding any of the sociodemographic variables or FEV1\%.

Symptoms of depression in parent caregivers as measured on the HADS Depression scale were comparable to those reported by the general population with $16.0 \%$ and $14.8 \%$ reporting at least borderline elevated scores, respectively. Results from the CES-D identified significantly more parent caregivers with elevated depression scores, compared to the general 


\section{$\underline{\text { Life satisfaction }}$}

Table 2 shows a comparison of the mean General and Health-related Life Satisfaction scores between the parent caregiver and community sample.

Insert Table 2 about here

Compared to the general population, parents caring for children with $\mathrm{CF}$ reported significantly less satisfaction on the following domains: Leisure Activities, General Health, Job Situation, Partnership/Sexuality, and General Life Satisfaction sum score ( $p=.001)$. However, in the domain of Family Life, parents described themselves as being more satisfied than the community sample ( $p=.003)$. In terms of health-related quality of life, parents of CF patients reported less satisfaction in the domains of Physical Condition, Ability to Relax, Energy/Zest for life, Freedom from Anxiety, Freedom from Aches/Pains and Independence of 
Help/Care, compared to the general population sample. The sum score for Health-related Life Satisfaction was also significantly lower in the parent than comparison sample $(p<.001)$. In the parent sample no significant differences in General and/or Health-related Life Satisfaction scores were found based on parental gender. Sociodemographic variables were not significantly correlated with general and health-related life satisfaction. Likewise, child lung function was not significantly associated with the parents' life satisfaction.

\section{$\underline{\text { Associations between symptoms of anxiety/depression and life satisfaction }}$}

Anxious and depressive symptoms were negatively correlated with general and healthrelated life satisfaction $(r=-.37--.60, p=.001)$. Univariate ANCOVAs, with the General and Health-related Life Satisfaction scores as the dependent variables and controlling for child age and lung function (which were inversely correlated, $r=-.24$ ), indicated that life satisfaction scores decreased when a concomitant increase of symptoms on the HADS Anxiety scale $(p<.001)$ and on the CES-D $(p<.001)$ was observed. Results are shown in table 3. Moderate effects were shown, with effect sizes ranging between $\eta^{2}=.077-.245$.

Insert Table 3 about here

\section{Discussion}

This is the first large scale, multi-center study to assess the prevalence of symptoms of anxiety, depression and life satisfaction in parents caring for children and adolescents with CF. Although it was shown that the majority of parents of children with CF was doing fairly well overall, the study results supported the central hypothesis, that anxious and depressive symptoms are more common in German parents of minors with CF than a community sample of adults matched by age and gender.

$\underline{\text { Anxious symptoms in parents }}$ 
As expected we found elevated levels of anxious symptoms in the parent sample compared to the comparison group. This result is in line with the recent US single-center, where up to $50 \%$ of the caregivers reported elevated levels of anxious symptoms ${ }^{17}$. The ongoing real or anticipated threat of the progressive and fatal nature of their child's disease may explain these feelings of tension and fear parents' experience. An examination of individual items indicated that the most frequent concerns were worries directed towards the future and feelings of tension and restlessness. This result parallels findings from studies of pediatric asthma patients and their parent caregivers. ${ }^{38,39}$

Special attention should be paid to the functionality of parents`anxiety and its potential positive effects on caregiving. Disease-specific anxiety may facilitate parental alertness and monitoring of symptoms and help them stay prepared for changes in their child's disease status, including worsening symptoms, signs of an acute exacerbation, and need for treatment changes. In other chronic conditions, such as asthma, caregiver anxiety was associated with an increased use of asthma services and hospitalizations. ${ }^{39}$ In a recent study of children with CF, co-morbid anxiety disorders and high levels of family cohesion were associated with better adherence to treatment. ${ }^{40}$ However, parental anxiety may also induce a disproportionate level of care and overprotection, ${ }^{41}$ which may lead to parent-teen conflict, e.g., adolescents desire for autonomy in managing their disease. ${ }^{42}$ The association between parental anxiety and disease management is an important area that needs further study. Another important issue is the familial pattern of symptoms of anxiety, as in general psychopathological symptoms are likely to aggregate in families ${ }^{4344}$ and thus, it is possible that anxious symptoms in caregivers beget anxious symptoms in the child or vice versa. We addressed this issue in a separate paper on symptoms of psychological distress in parent-child dyads which is currently under review.

\section{Depressive symptoms in parents}


Concerning the prevalence of depressive symptoms somewhat inconsistent results emerged. As predicted and in line with the international literature ${ }^{45461617}$, we found a higher prevalence of depressive symptoms in our parent sample compared to the general population . However, this was only true when the CES-D measure was applied using the international cut-off score of 16. Applying the adjusted national cut-off score of 24, which has been recommended for German samples,${ }^{31}$ results of the parent sample were comparable to those found in the control group and no significant group differences emerged. Thus, primarily using the broadly applied international cut-off score of 16 (which is part of the study methodology in order to allow for international comparisons) might lead to an overestimation of symptoms of depression in the German parent caregiver sample. The different thresholds for cut-points in this screening measure needs further study and should be kept in mind when conducting cross-cultural analyses of the international data set.

Using the Depression Scale of the HADS, parent data were comparable to those of the general population sample. A similar result was found for male caregivers of children with $\mathrm{CF}$ in the study by Driscoll and colleagues; $31 \%$ of the sample had elevated scores on the CES-D compared to only $14 \%$ on the HADS depression scale ${ }^{17}$. Methodical differences in the two measures likely explain these differential findings. The HADS does not include any somatic items, such as fatigue, which are clearly relevant for parent caregivers who take major responsibility for managing daily $\mathrm{CF}$ treatments. This is the reason for considering the CES-D to be the more appropriate and valid screening measure. The fact that nearly one-third of parents reported elevated symptoms of depression on this measure points to the need for a more thorough clinical examination, given evidence which suggests that depressive moods in parents are linked to adherence to treatments and thus, health outcomes in the child (for review see $\left.{ }^{15},{ }^{19}\right)$. These results indicate that annual screening of parents caring for a child with $\mathrm{CF}$, with referrals to mental health specialists when needed, should be initiated. In reporting 
back the screening results and offering further support a high degree of tactfulness and caution will certainly be needed in order to avoid opposition and defensiveness. Parents should not get the impression that they and their reactions to their child's progressive disease are characterized as psychologically abnormal, but rather as a normal reaction to the tremendous burden of being a parent of a child with $\mathrm{CF}$. In fact, the results underline the necessity for support programs tailored to the specific needs of parents caring for a chronically ill child.

It should also be noted that the vast majority of children were in good health, with $85 \%$ of children demonstrating no or only mild impairment of lung function, yet levels of both anxious and depressive symptoms were clinically elevated for a large number of parents. It is possible that despite the dramatic increase in life span for those diagnosed with $\mathrm{CF}$, recently projected as 37.4 years (CF Foundation Registry, 2008), it appears that management of the disease takes a toll on parent caregivers. Future longitudinal studies should focus on the course of the child's disease and its effects on parental functioning. It is possible that as the child's condition worsens, symptoms of depression in parent caregivers may increase further and require referral to mental health specialists. The comparison of those families with a sick child $(\mathrm{N}=17)$ to the rest of the sample points in this direction. No significant group differences were found, however, this is likely to be an effect of the small sample size, as the numerical differences in the scores clearly indicate higher levels of depressive (and anxious) symptoms in the group with acute medical conditions.

\section{$\underline{\text { Life satisfaction }}$}

Results on Life Satisfaction supported our hypothesis and converged with previous studies focusing on pediatric cancer patients, ${ }^{22,23}$ with parents reporting less Life Satisfaction compared to the community sample. In the General Life Satisfaction module, the worst life satisfaction was reported in the domains of Leisure Activities, Job Situation and 
Partnership/Sexuality. When interpreting these results, note that most of the respondents were mothers, who typically serve as the primary caregivers for their children and thus, have less time for their own activities. This is in line with other studies pointing out that parents caring for a child with CF have less time as a couple to engage in social and recreational activities ${ }^{3,4748}$. Interestingly, parents reported better satisfaction with their family life compared to the community sample. This finding also fits with prior literature on family adaptation to childhood cancer, in which families commonly report higher levels of closeness and family cohesion than families of healthy children. A study on the impact of a new diagnosis of a chronic illness yielded similar results for parental quality of life, ${ }^{21}$ concluding that coping with a child's chronic illness may strengthen family cohesion and decrease conflict, as parents utilize the emotional support of other family members in their adaptation process. Further, Health-Related Life Satisfaction in this parent sample was impaired in most of the life domains reported. This may be explained by the burden of everyday management of the disease, which results in excessive demands on parents (e.g., establishing good relationships with the $\mathrm{CF}$ healthcare team and integrating $\mathrm{CF}$ treatments into daily routines ${ }^{14}$ ) and increased fatigue. As expected, anxious and depressive symptoms were negatively correlated with General and Health-related Life Satisfaction and with higher levels of symptom severity, a finding that converges with others on quality of life in patients with $\mathrm{CF}$ and their families. ${ }^{49}$ $\underline{\text { Study limitations }}$

The strengths of this study include its multi-center design, large sample size and use of standardized screening measures. However, the study had also several limitations. First, we used data from comparison groups that were collected in previous studies. However, although we did not collect these data in a parallel manner, we successfully matched the community samples for age and gender. It is of course an interesting question whether or not parents caring for a child with CF should be compared to general population controls, given the very 
special circumstances and challenges of living with a chronically ill child which limit the comparability of these two groups. However, comparing parents of children with $\mathrm{CF}$ to a community sample seems to be a reasonable way to estimate the additional psychological distress of caring for a child with CF as opposed to "normal" levels of anxious and/or depressive symptoms. Unfortunately we have no information about the percentage of parents in the comparative populations. Thus, a biasing effect of being a parent could not be ruled out. Second, two widely used screening measures were employed to assess the prevalence of anxious and depressive symptoms, but these screening results were not further validated with a structured, clinical interview. Hence, it is important to note that the elevated rates of above cut-off screening results should not be mixed up with respective diagnoses of anxiety and/or depressive disorders but rather indicate that a more rigorous clinical assessment is warranted. Also, no multi-informant approach was used, but we only relied on parent self-report data. Additional selection biases may also have occurred in relation to which CF Centers in Germany decided to participate and which parents were recruited for the study. For example, in a sub-study in one clinical site of the German arm of the TIDES study ${ }^{50}$ the presence of a sample selection bias in terms of healthier persons being more likely to take part was shown. This allows for the suggestion, that the present results are rather underestimating the presence of symptoms of anxiety and/or depression requiring further clinical evaluation. Unfortunately, for practical reasons, we could not gather information on non-participants, which limits the generalizability of our results. However, the fact that we were able to recruit a large number of parents is supposed to counteract this threat to external validity.

The cross-sectional design of our study precluded the monitoring of how parental symptoms of anxiety, depression and life satisfaction affected long-term health outcomes. Future studies should investigate how changes in the child's health (e.g., acute exacerbations, new diagnosis of CF-related diabetes) affect parents' reports of psychological symptoms and 
quality of life. Thus, more complex, longitudinal studies are needed to examine the bidirectional nature of these relationships.

\section{$\underline{\text { Conclusions }}$}

These results provided evidence for the importance of measuring psychological symptoms and quality of life in parents caring for children with CF. Even though a huge part of the parents was doing fairly well overall, a significant proportion of caregivers was reporting borderline and clinical elevations of anxious and/or depressive symptoms. Therefore, systematic screening during routine care, followed by a more thorough clinical examination and the provision of psychosocial support and counselling if necessary may facilitate improved family functioning, which is likely to have positive effects on children's health outcomes.

\section{Acknowledgments}

The authors would like to thank all study centres and all patients and parent caregivers who participated in the current study for generously giving of their time and support. We also thank Paul Wenzlaff from the ZQM Hannover for his assistance with the analyses based on the registry data.

\section{Funding}

This study was supported by a financial grant from Mukoviszidose Institut gGmbH, Bonn, the research and development arm of the German Cystic Fibrosis Association Mukoviszidose e.V. 


\section{References}

1. Barlow JH, Ellard DR. The psychosocial well-being of children with chronic disease, their parents and siblings: an overview of the research evidence base. Child Care Health Dev 2006;32:19-31.

2. Kazak AE, Cant MC, Jensen MM, McSherry M, Rourke MT, Hwang WT, Alderfer MA, Beele D, Simms S, Lange BJ. Identifying psychosocial risk indicative of subsequent resource utilization in families of newly diagnosed pediatric oncology patients. J Clin Oncol 2003;21:3220-3225.

3. Quittner AL, Espelage D, Opipari L, Carter B, Eid N, Eigen H. Role strain in couples with and without a child with chronic illness: Association with marital satisfaction, intimacy, and daily mood. Health Psychol 1998;17:112-124.

4. Stern M, Sens B, Wiedemann B, Busse O, Damm G, Wenzlaff P. Qualitätssicherung Mukoviszidose. Überblick über den Gesundheitszustand der Patienten in Deutschland 2005. Berlin: Medizinisch Wissenschaftliche Verlagsgesellschaft; 2007.

5. Barker DH, Quittner AL. A biopsychosocial model of CF: Social and emotional functioning, adherence and quality of life. In: Allen J, Panitch H, Rubenstein R, editors. Lung Biology in Health and Disease Series: Cystic Fibrosis. New York: Informa Healthcare; 2010.

6. Rapoff MA. Adherence to pediatric medical regimens. New York: Kluwer Academic/Plenum Publishers; 1999.

7. Modi AC, Lim CS, Yu N, Geller D, Wagner MH, Quittner AL. A multi-method assessment of treatment adherence for children with cystic fibrosis. J Cyst Fibros 2006;5:177-185. 
8. Quittner AL, Drotar D, Ievers-Landis CE, Slocum N, Seidner D, Jacobsen J. Adherence to medical treatments in children with cystic fibrosis: The development and evaluation of family-based interventions. In: Drotar D, editor. Promoting adherence to medical treatments in childhood chronic illness: concepts, methods and interventions. Mahwah N.J.: Lawrence Earlbaum Associates; 2000.

9. Anthony H, Paxon S, Bines J, Phelan P. Psychosocial predictors of adherence of nutritional recommendations and growth outcomes in children with cystic fibrosis. J Psychosom Res 1999;47:623-634.

10. Modi AC, Marciel KK, Slater SK, Drotar D, Quittner AL. The influence of parental supervision on medical adherence in adolescents with cystic fibrosis: developmental shifts from pre to late adolescence. Child Health Care 2008;37:78-92.

11. Patterson JM, Budd J, Goetz D, Warwick WJ. Family correlates of a 10-year pulmonary health trend in cystic fibrosis. Pediatrics 1993;91:383-389.

12. Patterson JM, McCubbin HI, Warwick W. The impact of family functioning on health changes in children with cystic fibrosis. Soc Sci Med 1990;31:159-164.

13. Ievers CE, Drotar D. Family and parental functioning in cystic fibrosis. J Dev Behav Ped 1996;17:48-55.

14. Quittner AL, Barker DH, Marciel KK, Grimley ME. Cystic fibrosis: a model for drug discovery and patient care. In: Roberts MC, Steele RG, editors. Handbook of Pediatric Psychology. New York: Guilford Press; 2009. (pp.271-286).

15. Quittner AL, Barker DH, Snell C, Grimley ME, Marciel K, Cruz I. Prevalence and impact of depression in cystic fibrosis. Curr Opin Pulm Med 2008;14:582-588. 
16. Yilmaz O, Sogut A, Gulle S, Can D, Ertan P, Yuksel H. Sleep quality and depressionanxiety in mothers of children with two chronic respiratory diseases: Asthma and cystic fibrosis. J Cyst Fibros 2008;7:495-500.

17. Driscoll KA, Montag-Leifling K, Acton JD, Modi AC. Relations between depressive and anxious symptoms and quality of life in caregivers of children with cystic fibrosis. Pediatr Pulmonol 2009;44:784-92.

18. Quittner, A. L., Barker, D. H., Geller, D., Butt, S., and Gondor, M. Effects of maternal depression on electronically monitored enzyme adherence and changes in weight for children with CF. [abstract] J Cyst Fibros 2007;6(Suppl 1): S77.

19. Smith BA, Modi AC, Quittner AL, Wood L. Depressive symptoms in children with cystic fibrosis and parents and its effects on adherence to airway clearance. Pediatr Pulmonol 2010. Forthcoming.

20. Lawoko S, Soares JJF. Quality of life among parents of children with congenital heart disease, parents of children with other diseases and parents of healthy children. Qual Life Res 2003;12:655-666.

21. Goldbeck L. The impact of newly diagnosed chronic paediatric conditions on parental quality of life. Qual Life Res 2006;15:1121-1131.

22. Hatzmann J, Heymans HS, Carbonell A, van Praag BM, Grootenhuis MA. Hidden consequences of success in pediatrics: parental health-related quality of life--results from the Care Project. Pediatrics 2008;122. 
23. Klassen AF, Klaassen R, Dix D, Pritchard S, Yanofsky R, O'Donnell M, Scott A, Sung L. Impact of caring for a child with cancer on parents' health-related quality of life. J Clin Oncol 2008;26:5884-5889.

24. Goldbeck L, Besier T, Hinz A, Singer S, Quittner AL, and the TIDES study group. Prevalence of anxious and depressive symptoms in German patients with cystic fibrosis. Chest 2010;138:929-936.

25. Henrich G, Herschbach P. Questions on Life Satisfaction $\left(\mathrm{FLZ}^{\mathrm{M}}\right)$ - A short questionnaire for assessing subjective quality of life. Eur J Psychol Assess 2000;16:150159.

26. Zigmond AS, Snaith RP. The Hospital Anxiety and Depression Scale. Acta Psychiatr Scand 1983;67:361-370.

27. Herrmann C. International experiences with the hospital anxiety and depression scale - a review of validation data and clinical results. J Psychosom Res 1997;42:17-41.

28. Bjelland I, Dahl AA, Haug TT, Neckelmann D. The validity of the Hospital Anxiety and Depression Scale. An updated literature review. J Psychosom Res 2002;52:69-77.

29. Herrmann-Lingen C, Buss U, Snaith RP. HADS-D Hospital Anxiety and Depression Scale - Deutsche Version. 2nd ed. Bern: Huber; 2005.

30. Radloff LS. The CES-D scale: A self report depression scale for research in the general population. Appl Psychol Meas 1977;1:385-401.

31. Hautzinger M, Bailer M. Allgemeine Depressionsskala. 1st ed. Göttingen: Hogrefe; 1993. 
32. Herschbach P, Henrich G, Strasburger CJ, Feldmeier H, Marin F, Attanasio AM, Blum WF. Development and psychometric properties of a disease-specific quality of life questionnaire for adult patients with growth hormone deficiency. Eur J Endocrinol $2001 ; 145: 255-265$.

33. Goldbeck L, Schmitz TG. Comparison of three generic questionnaires measuring quality of life in adolescents and adults with cystic fibrosis: The 36-item short form health survey, the quality of life profile for chronic diseases, and the questions on life satisfaction. Qual Life Res 2001;10:23-36.

34. Goldbeck L, Zerrer S, Schmitz TG. Monitoring quality of life in outpatients with cystic fibrosis: feasibility and longitudinal results. J Cyst Fibros 2007;6:171-178.

35. Hinz A, Schwarz R. Angst und Depression in der Allgemeinbevölkerung. Psychotherapie Psychosomatik und medizinische Psychologie 2001;51:193-200.

36. Henrich G, Herschbach P. FLZ ${ }^{M}$ - Fragen zur Lebenszufriedenheit ${ }^{\text {Module }}$. Version für Erwachsene. Kurzbeschreibung und Vergleichsdaten. München: Klinik und Poliklinik für Psychosomatische Medizin, Psychotherapie und Medizinische Psychologie.; 2006.

37. Bortz J, Döring N. Forschungsmethoden und Evaluation für Human- und Sozialwissenschaftler. 4th ed. Heidelberg: Springer-Verlag; 2006.

38. Thoren CT, Petermann F. Reviewing asthma and anxiety. Respir Med 2000;94:409-415.

39. Brown ES, Gan V, Jeffress J, Mullen-Gingrich K, Khan DA, Wood BL, Miller BD, Gruchalla R, Rush AJ. Psychiatric symptomatology and disorders in caregivers of children with asthma. Pediatrics 2006;118:e1715-e1720. 
40. White T, Miller J, Smith GL, McMahon WM. Adherence and psychopathology in children and adolescents with cystic fibrosis. Eur Child Adolesc Psychiatry 2009; 18:96104.

41. Ullrich G, Wiedau-Görs S, Steinkamp G, Bartig HJ, Schulz W, Freihorst J. Parental fears of Pseudomonas infection and measures to prevent its acquisition. J Cyst Fibros $2002 ; 1: 122-130$.

42. Smith BA, Shuchman M. Problem of nonadherence in chronically ill adolescents: strategies for assessment and intervention. Curr Opin Pediatr 2005;17:613-618.

43. Kendler KS, Davis CG, Kessler RC. The familial aggregation of common psychiatric and substance use disorders in the National Comorbidity survey: A family history study. Br J Psychiatry 1997;170:541-548.

44. Lieb R, Isensee B, Höfler M, Pfister H, Wittchen H-U. Parental major depression and the risk of depression and other mental disorders in offspring. Arch Gen Psychiatry 2002;59:365-374.

45. Quittner AL, Slater S. Parenting stress, depression, and caregiving for young children with cystic fibrosis. Ped Pulmonol 2005;28:180-181.

46. Glasscoe C, Lancaster GA, Smyth RL, Hill J. Parental depression following the early diagnosis of cystic fibrosis: a matched, prospective study. J Pediatr 2007;150:185-191.

47. Quittner AL, Opipari LC, Regoli MJ, Jacobsen J, Eigen H. The impact of caregiving and role strain on family life: Comparisons between mothers of children with cystic fibrosis and matched controls. Rehabil Psychol 1992;37:275-290. 
48. Modi AC, Quittner AL. Utilizing computerized phone diary procedures to assess health behaviors in family and social contexts. Child Health Care 2006;35:29-45.

49. Staab D, Wenninger K, Gebert N, Rupprath K, Bisson S, Trettin M, Paul KD, Keller KM, Wahn U. Quality of life in patients with cystic fibrosis and their parents: what is important besides disease severity? Thorax 1998;53:727-731.

50. Ullrich G, Wünderich R, Ammon M, Ballmann M, Bartig HJ. Extending the TIDES-CF Study to a health services research approach. In: Ullrich G, editor. Psychology in Medical Settings: Lung Transplantation and Cystic Fibrosis. Norderstedt: Books-ondemand; 2010. (pp 107-130). 


\section{Figure Legends}

Fig.1: Frequency of elevated scores on the HADS Anxiety Scale (ANX, normal: 0-7, borderline: $8-10$, abnormal: $\geq 11$ ) and the CES-D (DEPR, normal: 0-15, borderline/international cut-off: $16-23$, abnormal/German cut-off: $\geq 24$ ) in the parent sample (parents) and in the general population sample (gen.pop.) 
Anxiety, depression, and life satisfaction in parents caring for children with cystic fibrosis

Manuscript draft for Pediatric Pulmonology - December 2010

Tanja Besier, $\mathrm{PhD}^{1}$, Anja Born, M.Sc ${ }^{2}$, Gerhard Henrich, $\mathrm{PhD}^{3}$, Andreas Hinz, $\mathrm{PhD}^{2}$,

Alexandra L. Quittner, $\mathrm{PhD}^{4}$, Lutz Goldbeck, $\mathrm{PhD}^{1}$, and the TIDES study group

${ }^{1}$ University Hospital Ulm, Department of Child and Adolescent Psychiatry/Psychotherapy,

${ }^{2}$ University of Leipzig, Independent Department for Medical Psychology and Medical

Sociology, ${ }^{3}$ University Hospital of the Technical University Munich, Department of

Psychosomatic Medicine, ${ }^{4}$ University of Miami, Department of Psychology

All correspondence concerning this article should be addressed to Tanja Besier, $\mathrm{PhD}$,

University Hospital Ulm, Department of Child and Adolescent Psychiatry/Psychotherapy,

Steinhoevelstr. 5, 89075 Ulm, Germany. Email: tanja.besier@ uniklinik-ulm.de

Running head: Psychopathology in parents of minors with CF 


\begin{abstract}
Objective To assess the prevalence of symptoms of anxiety and depression and the extent of life satisfaction in parents caring for children with cystic fibrosis (CF) in Germany.

Methods The study included 650 caregivers of 564 children with CF ages 0 to 17, who completed the Hospital Anxiety Depression Scale (HADS), the Center for Epidemiologic Studies Depression Scale (CES-D) and the Questions on Life Satisfaction (FLZ ${ }^{\mathrm{M}}$ ).

Results More than one-third (37.2\%) of parents showed elevated levels of anxious symptoms, compared to $18.9 \%$ of a population sample $(p \leq .001)$ and significantly more parents reported elevated levels of depressive symptoms compared to a community sample (28\% vs. $21 \%$, $p=.01$ ). Higher levels of anxious and depressive symptoms were associated with lower life satisfaction $(p<.001)$.

Conclusions High levels of anxious and depressive symptoms among parents of children with $\underline{\mathrm{CF}}$ suggested that annual symptom screening is warranted. This will facilitate identification of those at risk and provide referrals and intervention for those who are in need of it.
\end{abstract}

Keywords: Anxiety; cystic fibrosis; depression; life satisfaction; parent caregivers. 


\section{Introduction}

Chronic medical conditions, such as cystic fibrosis (CF), have significant implications for the psychosocial well-being of the family system. .1 Parents of children with chronic

illnesses must cope with uncertainty about progression of the disease, as well as challenges in everyday life, including adherence to complex treatment regimens, regular clinic visits,

hospitalizations, financial stress due to costs of care, and disruptions in future plans $\underset{\mathbf{2} \mathbf{x}}{\mathbf{2}} \mathrm{As}$ a consequence of these caregiving challenges, parents are at a high risk for the development of psychological symptoms and decreased quality of life. $\cdot \frac{3}{v}$

Advances in medical care and treatments over the past 20 years have led to an increase in life span of patients with $\mathrm{CF}$, with a majority of children in developed countries now living into adulthood $\frac{4}{\mathrm{~s}}$ However, management of CF requires adherence to a complex and timeconsuming treatment regimen, including inhaled and oral medications, airway clearance, and alterations in diet $\cdot \frac{5}{3}$ In general, poor adherence ( $50 \%$ or less) is reported in chronically ill pediatric populations ${ }^{6}$ and this was also shown for children with $\mathrm{CF}^{7}$. Adherence rates in children with CF vary depending on the specific treatment component, with adherence for chest physical therapy rated between $40-47 \%{ }^{8}$ and approximately $51 \%$ in a newer US study ${ }^{7}$ and estimates being especially low for dietary recommendations ${ }^{9}$. Non-adherence can have serious consequences for the child's health status. Therefore, depending on the child's development, parents must take responsibility for administering and supervising the specific

Formatted: Superscript Deleted: $^{3}$

Deleted: CF is the most common lifeshortening, recessively inherited condition among Caucasian populations, currently affecting about 30,000 patient in the United States.

Formatted: Superscript

Deleted: ${ }^{4}$

Formatted: Superscript

$\underline{\mathrm{CF}}$ treatments, which has been shown to increase role strain in parents and lead to greater conflict with adolescents $\frac{3,3,10}{1}$ Studies have demonstrated that parents' symptoms of

depression and anxiety, as well as general family functioning show a strong association with health outcomes in patients with $\mathrm{CF} \frac{11.12}{1}$ These findings suggest that the impact of $\mathrm{CF}$ on
Formatted: Superscript Formatted: Superscript Formatted: Superscript

Deleted: D

Deleted: these 
From the late 1960s on, studies have examined the impact of CF on parents/caregivers (for review see $\frac{13,14}{2-1}$ ) with most studies finding high levels of psychological distress and increased risk of depressive symptoms $\frac{15}{4}$ A Turkish study on sleep quality and the psychological well-being of mothers caring for children with asthma or CF reported higher anxiety and depression scores than mothers of healthy children. 16 A single center study in the US examining the relations between symptoms of psychological distress and quality of life in caregivers of children with $\mathrm{CF}^{17}$ found elevated rates of depressive and anxious symptoms, which were negatively correlated with parental quality of life. Rates of anxious symptoms were more pronounced (43-51\%) compared to $14-31 \%$ (depending of the measure used) of the parents reporting elevated levels of depressive symptoms. In another US study, over onethird of parents scored in the elevated range on a depression measure and more symptoms of depression were associated with worse adherence to enzymes as well as either loss of weight or failure to make expected weight gains in children with $\mathrm{CF}$ three months later ${ }^{18}$ Similarly, a single center study from Smith and colleagues found $35 \%$ of mothers and $23 \%$ of fathers reported elevated symptoms of depression and $57 \%$ of mothers and $25 \%$ of fathers reported elevated anxiety. Further, symptoms of depression in parents of school-age children were associated with worse adherence to airway clearance $\frac{19}{5}$

Research has also shown that caring for a child with a chronic condition can negatively affect parents' quality of life, $\frac{20,21}{2}$ as they are confronted with the threat of a lifelimiting illness and additionally have to face multiple social and emotional stressors associated with their child's disease, e.g., fear, less time for social activities, financial burdens, etc. Also, parents` health-related quality of life proved to be worse than that reported by parents of healthy children $\frac{22.23}{{ }_{1}-}$ However, specific studies on the health-related quality of life of parents caring for a child with $\mathrm{CF}$ are rare. In the single-center study by Driscoll and colleagues already mentioned above, a good child lung functioning was
Deleted:

Deleted: ${ }^{9,10}$

Formatted: Superscript

Formatted: Superscript Deleted: ${ }^{11}$

Deleted: recently published

Deleted: ${ }^{12}$

Formatted: Superscript

Formatted: Superscript
Formatted: Superscript

Deleted: ${ }^{11}$

Deleted: in the US 
associated with better quality of life in mothers caring for a child with CF. Depressive and anxious symptoms predicted parental quality of life, even after controlling for psychosocial treatment received by the caregiver. However, the relation was stronger between depressive symptoms and quality of life ${ }^{17}$.

To date, no large scale epidemiological studies have systematically examined the

prevalence of anxiety and depression and subjectively reported quality of life of parents caring for a child with CF. Therefore "The International Depression/Anxiety Epidemiological Study" (TIDES, www.tides-cf.org) was initiated in 2007 with more than ten countries worldwide participating so far. The objectives were to screen for depressive and anxious symptoms in adolescent and adult patients with $\mathrm{CF}$ and parents caring for a minor child with $\underline{\mathrm{CF}}$, and to link these psychological data to the patients` health outcomes. Here, parent data from the German arm of the study including $32 \mathrm{CF}$ Centers are presented. The patient data have been published elsewhere ${ }^{24}$ Standardized screening tools were used to estimate the prevalence of anxious and depressive symptoms in parents caring for a child with CF. Further, rather than evaluating the broader concept of quality of life, the focus was on assessment of Deleted: In this large-scale study Deleted: at 32 CF Centers in Germany Deleted:

life satisfaction, defined as subjectively perceived quality of life based on individual

preferences and reported satisfaction in multiple life domains. $\frac{25}{4}$

Thus, the purpose of the current study was to test the following hypotheses using a large, nationally representative sample:

1. Compared to the general population, symptoms of anxiety and depression were expected to be more prevalent in parent caregivers of minors (under age 18 years) with CF.

2. Life satisfaction was expected to be lower in parent caregivers of minors with $\mathrm{CF}$ than in the general population. 
3. Among parents, a significant negative association was expected between symptoms of anxiety/depression and life satisfaction.

\section{Materials and Methods}

\section{Procedure}

Data collection took place between February 2007 and April 2008. The study protocol was approved by the Institutional Review Board of the University of Ulm and the local IRBs at the 32 participating CF clinics (representing about one third of the German CF outpatient units). This study was part of a larger international prevalence study initiated in the United States (see www.tides-cf.org). During routine clinic visits, parents of children with CF ages 0 to through 17 were informed of the study's purpose and objectives and were asked to participate. After completion of informed consent, a demographics questionnaire and screening instruments (see below) for symptoms of anxiety/depression and life satisfaction were administered by a member of the $\mathrm{CF}$ team, such as a social worker, psychologist, or nurse. Anxious and depressive symptoms in parents were measured with the Hospital Anxiety and Depression Scale (HADS). Additionally, to measure parental depressive symptoms, the CES-D was administered, as the HADS Depression scale excludes relevant somatic items (e.g., fatigue). Thus, the CES-D was considered the primary measure and more appropriate screener for depressive symptoms. The Questions on Life Satisfaction $\left(\mathrm{FLZ}^{\mathrm{M}}\right)$ were used to evaluate parental life satisfaction. Completion of the questionnaires took about 20 minutes. The measures were scored immediately upon completion and if the participant scored above the clinical cut-off score ( $\geq 8$ points) on either the anxiety or depression scale, a referral to a mental health professional was initiated.

Parents also agreed to the collection of medical data on their child with $\mathrm{CF}$, which

Deleted: and these data were extracted from the German CF registry. The variables extracted were current height, 
weight, FEV1 in liters, FEV1\% predicted, colonization with germs (Pseudomonas aeruginosa yes/no; Burkholderia cepacia yes/no), complications during the last year (hemoptysis yes/no, pneumothorax yes/no or new diagnosis of CF-related Diabetes yes/no).

\section{Measures}

Hospital Anxiety and Depression Scale (HADS)

The HADS 26 is a brief and easy to administer 14-item instrument which measures symptoms of anxiety ( 7 items) and depression ( 7 items). It was designed specifically for use with chronically ill patients and therefore, physical symptoms (such as headaches or fatigue) that could be associated with a medical condition were excluded. The instrument has been translated into numerous languages and has been used extensively in different countries with different populations. Respondents rate each symptom using a 4-point scale (range 0-3), indicating the current extent of the symptom. Results of this screening measure can be analysed both categorically, discriminating normal ( $0-7$ points), borderline (8-10 points) and clinical levels of symptoms ( $\geq 11$ points) as indicated by cut-off scores provided by the authors, and dimensionally by adding the raw scores of each scale.

The HADS has extensive reliability and validity data ${ }^{27,28}$ with strong internal consistency as measured by Cronbach's $\alpha$ of .82 for the Anxiety subscale (HADS-A) and .83 for the Depression subscale (HADS-D) in the current sample. Optimal sensitivity and specificity (approximately .80 each) was achieved most frequently using a cut-off score of 8 for the Anxiety scale $\frac{28}{2}$ External validity has been demonstrated, with strong convergence found between the HADS and other validated anxiety and depression measures. In this study, the German version of the HADS $\frac{29}{x}$ was administered.

\section{Center of Epidemiologic Studies Depression Scale (CES-D)}

The Center for Epidemiologic Studies Depression Scale, CES-D 30 is a frequently used 20item self-report instrument screening for the major components of depression, including
Formatted: Font: Italic

Deleted: Mellitus

\section{Deleted: Subjects}

Parents of children and adolescents with CFII

A total of 650 parent caregivers $(75.5 \%$ mothers) of 564 minors with $\mathrm{CF}$ (0-17 years, $M=9.5, S D=4.6 ; 54.9 \%$ male) were consecutively recruited for the study during a routine clinic visit at their $\mathrm{CF}$ center. Participating patients were compared to those not participating in this study, but whose data are included in the German CF Registry. These data included socio-demographic (e.g., age, gender, education, living situation) and medical information (e.g., height, weight, $\mathrm{FEV}_{1} \%$ ). Fewer parents with children under the age of 6 years $(\mathrm{p}<.001)$ participated in this study than were represented in the Registry, and thus there were a few differences on age-correlated indicators (lower height and weight in the study sample, as expected for this age group). No other group differences were found, indicating that this sample was representative of the school-age and adolescent CF cohort in Germany. II

In 478 cases, data were obtained from only one parent (73 fathers, 405 mothers), whereas we received two data sets (one from father, one from mother) for the remaining 86 children. Children's lung function, measured as $\mathrm{FEV}_{1} \%$ predicted, ranged from $15.7 \%$ to $138.7 \%$

$(\mathrm{M}=89.8 \%, \mathrm{SD}=21.1)$, with $83.2 \%$ of the children falling in the normal to mild range of disease severity $\left(\mathrm{FEV}_{1} \% \geq 70\right)$ and only $2.5 \%$ falling in the severely impaired range $\left(\mathrm{FEV}_{1} \% \leq 40\right)$. Table 1 shows the characteristics of the parent sample, separately for mothers and fathers. II

Insert Table 1 about here $\mathscr{I}$

Normative data from the German general population II

To allow for group comparisons, we used the most recent instrument-specific data from normative reference samples. For the screening of anxiety, we used data

from a German survey study ${ }^{20}$ The general population sample was selected based on 216 sample points in Ger ... [1]

Formatted: Superscript

Deleted: ${ }^{22}$

Deleted: ${ }^{23,24}$

Formatted: Superscript

Formatted: Superscript Deleted: ${ }^{24}$

Deleted: Anxiety scale

Formatted: Superscript

Deleted: ${ }^{25}$

Deleted: al

Deleted: ${ }^{26}$

Formatted: Superscript 
depressive mood, feelings of guilt and worthlessness, loss of appetite, and sleep disturbance. It was designed to assess all major symptoms of depression in community samples and has excellent psychometric properties, evidencing good internal consistency (Cronbach's $\alpha=.89$ in the current sample). For each item, respondents rate the frequency of their symptoms over the past week on a 4-point scale ranging from 0-3. All items scores are summed to yield a total score, ranging from 0-60. Higher scores indicate more depressive symptoms, with a score of 16 or higher identified as the clinical cut-off score for depressive symptoms $\frac{30}{4}$ In this study, the German version of the CES-D ${ }^{31}$ was administered. In the German manual the use of an adapted cut-off score of 24 or higher is suggested, referring to a large but non

Formatted: Superscript Deleted: ${ }^{26}$ representative community sample. To allow for international comparability, both, the international cut-off score of 16 and the German cut-off score of 24 were applied in this study.

\section{Questions on Life Satisfaction $\left(\mathrm{FLZ}^{\mathrm{M}}\right)$}

The Questions on Life Satisfaction (German: Fragen zur LebensZufriedenheit, FLZ $^{\mathrm{M} 25}$ ) is a multidimensional measure of General and Health-related Life Satisfaction in eight domains of daily life (e.g., leisure time/hobbies, family life, physical condition, ability to relax, etc.). The instrument includes ratings of the subjective importance for each domain, which can be used to weight ratings of satisfaction. Each domain is evaluated twice, once for the importance and once for satisfaction, on 5-point rating scales ranging from 1 (not important/dissatisfied) to 5 (extremely important/very satisfied). Weighted scores for each item are then calculated using the following formula: weighted satisfaction $=($ importance rating -1$) \times((2 x$ satisfaction rating)-5). $\frac{25}{-1}$ Item-specific weighted scores range from -12 to +20 , with negative scores indicating dissatisfaction with the domain measured. Domains without subjective importance are weighted 0 , and thus do not impact the individual's life satisfaction. Total scores for General and Health-related Life Satisfaction are computed by summing the eight general and 
1

2

3

4

5

6

7

8

9 eight health-related domain scores, and they range from -96 to +160 . Higher scores indicate better satisfaction with life. Good reliability and validity of the $\mathrm{FLZ}^{\mathrm{M}}$ has been reported in previous studies using the instrument with adolescent and adult populations $\frac{25,32-34}{-2} \operatorname{In}$ the current sample Cronbach's $\alpha$ was .83 for the General Life Satisfaction module and .88 for the Health-related Life Satisfaction module.

\section{Statistical analyses}

To allow for group comparisons, we used the most recent instrument-specific data from normative reference samples. For the HADS data, we used data from a German survey study ${ }^{35}$ The general population sample was selected based on 216 sample points in Germany using the random-route-technique (random selection of street, house, flat and target subject in the household). This sample, with a response rate of $68 \%$, can be assumed to be representative of the adult German population living in private households. Individuals from foreign countries were not included in the sample because of problems with command of the German language. The original sample, with complete data consisted of 2037 people aged 14-92 years, with a mean age of $49.2(\mathrm{SD}=17.3)$. These respondents were matched for age and gender with our parent sample, leading to a sample size of 614 (22-60 years, $M=40.0$ years, $S D=7.2$, $\underline{76.4 \% \text { female). }}$.

To analyse the CES-D data we used comparative data from a representative population sample in cooperation with the German study group mentioned above ( $N=2005,14-91$ years, $M=48.0, S D=18.3)$. Matching for age and gender led to a sample size of 620 people aged 2160 years ( $M=40.0$ years, $S D=7.3,76.6 \%$ female).

The life satisfaction data, measured with the Questions on Life Satisfaction $\left(\mathrm{FLZ}^{\mathrm{M}}\right)$, were also compared to community samples. For the general life satisfaction module, data came from a large community sample $(N=5036,14-92$ years, $M=48.4, S D=18.0,53.7 \%$ female). Comparison data for the health-related life satisfaction module came from the FLZ

\section{Deleted:}

Deleted: (Cronbach's $\alpha=.82-.89$ )

Deleted: ${ }^{19,28-30}$

Formatted: Superscript

Formatted: Font: Italic
Formatted: Indent: First line: 35.4 pt

Formatted: Superscript 
standardization study ${ }^{36}$ with 1338 German adults from the community (17-95 years, $M=46.9$,

$S D=17.2,54.6 \%$ female). An analogous matching procedure was completed for both samples, $\underline{\text { selecting those participants with an age-gender combination paralleling the parent caregiver }}$ sample. Their responses were weighted so that the age and gender distribution in the two community samples paralleled the distribution in the parent caregiver sample. The matching procedure resulted in a sample of 2718 subjects for the general life satisfaction module and $\underline{768 \text { subjects for the health-related life satisfaction module. }}$

The frequencies of elevated HADS Anxiety and Depression scores and CES-D scores were calculated using the established cut-off scores. Group comparisons with the community sample, matched for age and gender, were performed using $\chi^{2}$-tests. Gender differences comparing the mean scores of mothers and fathers were determined using Student's $t$-tests. Associations of elevated levels of anxious/depressive symptoms and the following sociodemographic and disease-related variables were determined applying Chi square tests or $t$ tests for independent samples: parent education $(0=10$ years of school or less, $1=$ "Abitur" or university degree), parent employment ( $0=$ no employment outside of the home, $\underline{1=e m p l o y m e n t ~ o u t s i d e ~ o f ~ t h e ~ h o m e), ~ p a r e n t ~ a g e, ~ c h i l d ~ a g e, ~ a n d ~ F E V 1 \% ~ a s ~ i n d i c a t o r ~ f o r ~ c h i l d ~}$ health status. FLZ $^{\mathrm{M}}$ raw scores were transformed into weighted scores and two total scores were calculated for General and Health-related Life Satisfaction. Student's $t$-tests for independent samples were used to examine potential differences between the parent and matched community sample. Spearman's rho was used to test the associations between life satisfaction and the same sociodemographic and disease-related variables that were used to explore the associations with parental anxious and/or depressive symptoms. To test the associations among symptoms of anxiety and depression and life satisfaction, univariate analyses of covariance (ANCOVAs) were calculated with the level of anxious symptoms (normal - borderline - abnormal) and depressive symptoms as measured with the CES-D 
1

2

3

4

5

6

7

8

9 (normal-abnormal international-abnormal $_{\text {German }}$ ) as independent variables and General and Healthrelated Life Satisfaction scores as dependent variables, controlling for child age and lung function (FEV1\%). In those cases with double data sets (mother and father filled in a questionnaire) we randomly selected only one parent for inclusion in the ANCOVA model in order to avoid data dependency. Effect sizes were calculated using $\eta^{2}$, with $\eta^{2}>.01$ as small, $\eta^{2}>.10$ as medium and $\eta^{2}>.25$ as large effects. $\frac{37}{2}$ All statistical analyses were conducted with Deleted: $^{31}$

Formatted: Superscript the software package SPSS version 12.0 for Windows.

Results

\section{Sample Characteristics}

A total of 650 parent caregivers of 564 minors with $\mathrm{CF}(0-17$ years, $M=9.5, S D=4.6$;

$54.9 \%$ male) were consecutively recruited for the study during a routine clinic visit at their $\mathrm{CF}$ center. This was approximately $50 \%$ of all eligible families at the participating sites. Reasons for non-participation included no time, no interest in the study, data protection concerns, etc. In 478 cases, data were obtained from only one parent ( 73 fathers, 405 mothers), whereas we received two data sets (one from father, one from mother) for the remaining 86 children. Children's lung function, measured as $\mathrm{FEV}_{1} \%$ predicted, ranged from $15.7 \%$ to $138.7 \%$ $(\mathrm{M}=89.8 \%, \mathrm{SD}=21.1)$, with $83.2 \%$ of the children falling in the normal to mild range of disease severity $\left(\mathrm{FEV}_{1} \%>70\right)$ and only $2.5 \%$ falling in the severely impaired range ( $\mathrm{FEV}_{1} \%$ <40). In 17 cases (3.1\%) the patients were experiencing acute medical conditions. The parents of these patients were included in the study sample; however, comparisons were made to the rest of the parents whose children were currently not sick or experiencing pulmonary exacerbations. Table 1 shows the characteristics of the parent sample, separately for mothers and fathers.

Insert Table 1 about here 

data are included in the German CF Registry. These data included socio-demographic (e.g., age, gender, education, living situation) and medical information (e.g., height, weight, $\left.\underline{\mathrm{FEV}}_{1} \%\right)$. Fewer parents with children under the age of 6 years $(\mathrm{p}<.001)$ participated in this $\underline{\text { study than were represented in the Registry, and thus there were a few differences on age- }}$ correlated indicators (lower height and weight in the study sample, as expected for this age group). No other group differences were found, indicating that this sample was representative of the school-age and adolescent CF cohort in Germany.

\section{Symptoms of anxiety and depression}

Parents of children with CF reported significantly more symptoms of anxiety than the genctis general population (see figure 1). At least borderline elevations in anxious symptoms were reported by $37.2 \%$ of parent caregivers, with $17.0 \%$ in the clinical range. In contrast, only $18.9 \%$ of the general population reported borderline symptoms and $5.2 \%$ reported symptoms in the clinical range $\left(\chi^{2}=59.208, p<.001\right)$. Among parents, the most frequently reported items on the Anxiety scale were "I feel restless as I have to be on the move" $(M=1.16, S D=1.0)$, "I get a sort of frightened feeling as if something awful is about to happen" $(M=1.16, S D=0.9)$, and "I feel tense or wound up" $(M=1.15, S D=0.8)$. In general, mothers of children with $\mathrm{CF}$ reported significantly more anxious symptoms than fathers (mothers: $M=6.7, S D=3.9$ versus fathers: $M=5.9, S D=3.7, t=-2.29, p=.02)$. There were no significant differences in anxious symptoms regarding any of the sociodemographic variables or FEV1\%.

\section{Symptoms of depression in parent caregivers as measured on the HADS Depression} scale were comparable to those reported by the general population with $16.0 \%$ and $14.8 \%$ reporting at least borderline elevated scores, respectively. Results from the CES-D identified 
$\underline{\text { significantly more parent caregivers with elevated depression scores, compared to the general }}$ population sample, using the international cut-off score of 16. Twenty-eight percent of parents caring for a child with CF reported clinically elevated symptoms of depression on the CES-D compared to $21 \%$ in the general population $\left(\chi^{2}=6.339, p=.01\right.$, see figure 1$)$. Applying the German cut-off score of 24, no significant group differences could be found.

\section{Insert figure 1 about here}

In the parent sample, the most frequently reported items included worries about the future ( $M=1.21, S D=1.1)$, feelings of being not as good as other people $(M=1.10, S D=1.2)$, and problems feeling happy $(M=1.03, S D=1.0)$ and enjoying life $(M=1.03, S D=1.0)$. No significant gender difference was found in the level of depressive symptoms reported in the parent sample $\left(t_{[598)}=-1.20, p=.23\right)$. More caregivers with elevated depressive symptoms had a low educational status $\left(\chi^{2}=7.749, p<.01\right)$. There were no significant differences on any of the other sociodemographic variables or child lung function (FEV1\%).

\section{Life satisfaction}

Table 2 shows a comparison of the mean General and Health-related Life Satisfaction scores between the parent caregiver and community sample.

\section{Insert Table 2 about here}

Compared to the general population, parents caring for children with CF reported

significantly less satisfaction on the following domains: Leisure Activities, General Health, Job Situation, Partnership/Sexuality, and General Life Satisfaction sum score ( $p=.001)$.

However, in the domain of Family Life, parents described themselves as being more satisfied than the community sample ( $p=.003)$. In terms of health-related quality of life, parents of CF patients reported less satisfaction in the domains of Physical Condition, Ability to Relax, Energy/Zest for life, Freedom from Anxiety, Freedom from Aches/Pains and Independence of 
Help/Care, compared to the general population sample. The sum score for Health-related Life

Satisfaction was also significantly lower in the parent than comparison sample $(p<.001)$.

In the parent sample no significant differences in General and/or Health-related Life

Formatted: Indent: First line: 35.4

pt, Line spacing: Double

$\underline{\text { Satisfaction scores were found based on parental gender. Sociodemographic variables were }}$

$\underline{\text { not significantly correlated with general and health-related life satisfaction. Likewise, child }}$

lung function was not significantly associated with the parents' life satisfaction.

Formatted: Indent: First line: 35.4

$\underline{\text { Associations between symptoms of anxiety/depression and life satisfaction }}$

Anxious and depressive symptoms were negatively correlated with general and health-

related life satisfaction $(r=-37--.60, p=.001)$. Univariate ANCOVAs, with the General and

Health-related Life Satisfaction scores as the dependent variables and controlling for child age

and lung function (which were inversely correlated, $r=-.24$ ), indicated that life satisfaction

Formatted: Font: Italic

scores decreased when a concomitant increase of symptoms on the HADS Anxiety scale

$(p<.001)$ and on the CES-D ( $p<.001)$ was observed. Results are shown in table 3. Moderate

effects were shown, with effect sizes ranging between $\eta^{2}=077-245$.

Insert Table 3 about here

Deleted: Anxiety

Deleted: depression

Deleted: 38

Deleted: and $r=-.55, p=.01$

respectively

Deleted: 2

Deleted: 068

Deleted: 237

Deleted: 2

Deleted:

Discussion

This is the first large scale, multi-center study to assess the prevalence of symptoms of anxiety, depression and life satisfaction in parents caring for children and adolescents with

CF. Although it was shown that the majority of parents of children with CF was doing fairly

well overall, the study results supported the central hypothesis, that anxious and depressive

Deleted: $\mathrm{T}$

symptoms are more common in German parents of minors with CF than a community sample

of adults matched by age and gender.

Deleted: Parental anxiety

Anxious symptoms in parents 
As expected we found elevated levels of anxious symptoms in the parent sample

compared to the comparison group. This result is in line with the recent US single-center, where up to $50 \%$ of the caregivers reported elevated levels of anxious symptoms ${ }^{17}$. The ongoing real or anticipated threat of the progressive and fatal nature of their child's disease may explain these feelings of tension and fear parents' experience. An examination of individual items indicated that the most frequent concerns were worries directed towards the future and feelings of tension and restlessness. This result parallels findings from studies of pediatric asthma patients and their parent caregivers. $\frac{38,39}{-3}$

Special attention should be paid to the functionality of parents` anxiety and its potential positive effects on caregiving. Disease-specific anxiety may facilitate parental alertness and monitoring of symptoms and help them stay prepared for changes in their child's disease status, including worsening symptoms, signs of an acute exacerbation, and need for treatment changes. In other chronic conditions, such as asthma, caregiver anxiety was associated with an increased use of asthma services and hospitalizations $\frac{39}{2}$ In a recent

Deleted:

Formatted: Superscript Deleted: $^{33}$ study of children with CF, co-morbid anxiety disorders and high levels of family cohesion were associated with better adherence to treatment $\frac{40}{4}$ However, parental anxiety may also induce a disproportionate level of care and overprotection, $\frac{41}{}$ which may lead to parent-teen conflict, e.g., adolescents desire for autonomy in managing their disease. $\frac{42}{}$ The association between parental anxiety and disease management is an important area that needs further study. Another important issue is the familial pattern of symptoms of anxiety, as in general psychopathological symptoms are likely to aggregate in families ${ }^{43,44}$ and thus, it is possible that anxious symptoms in caregivers beget anxious symptoms in the child or vice versa. We addressed this issue in a separate paper on symptoms of psychological distress in parent-child dyads which is currently under review.

Depressive symptoms in parents

Formatted: Superscript
Deleted: ${ }^{34}$
Deleted: ${ }^{35}$

Deleted: ${ }^{36}$ 


\section{Concerning the prevalence of depressive symptoms somewhat inconsistent results} emerged. As predicted and in line with the international literature ${ }_{16,17,45,46}$ we found a higher prevalence of depressive symptoms in our parent sample compared to the general population . However, this was only true when the CES-D measure was applied using the international cut-off score of 16. Applying the adjusted national cut-off score of 24, which has been recommended for German samples ${ }^{31}$ results of the parent sample were comparable to those found in the control group and no significant group differences emerged. Thus, primarily using the broadly applied international cut-off score of 16 (which is part of the study methodology in order to allow for international comparisons) might lead to an overestimation of symptoms of depression in the German parent caregiver sample. The different thresholds for cut-points in this screening measure needs further study and should be kept in mind when conducting cross-cultural analyses of the international data set.

Using the Depression Scale of the HADS, parent data were comparable to those of the general population sample. A similar result was found for male caregivers of children with $\mathrm{CF}$ in the study by Driscoll and colleagues; $31 \%$ of the sample had elevated scores on the CES-D compared to only $14 \%$ on the HADS depression scale ${ }^{17}$. Methodical differences in the two measures likely explain these differential findings. The HADS does not include any somatic items, such as fatigue, which are clearly relevant for parent caregivers who take major responsibility for managing daily $\mathrm{CF}$ treatments. This is the reason for considering the CES-D to be the more appropriate and valid screening measure. The fact that nearly one-third of parents reported elevated symptoms of depression on this measure points to the need for a more thorough clinical examination, given evidence which suggests that depressive moods in parents are linked to adherence to treatments and thus, health outcomes in the child (for review see 15 . 19 . These results indicate that annual screening of parents caring for a child with $\underline{\mathrm{CF}}$, with referrals to mental health specialists when needed, should be initiated. In reporting
Deleted: ${ }^{11}$

Deleted:

Formatted: Superscript

Formatted: Superscript

Deleted: clinically

Deleted: is alarming

Deleted: depression

Deleted: caregivers

Formatted: Superscript Deleted: ${ }^{11}$

Formatted: Superscript Deleted: ${ }^{13}$

Deleted: caregiver 
back the screening results and offering further support a high degree of tactfulness and caution will certainly be needed in order to avoid opposition and defensiveness. Parents should not get the impression that they and their reactions to their child's progressive disease are characterized as psychologically abnormal, but rather as a normal reaction to the tremendous burden of being a parent of a child with CF. In fact, the results underline the necessity for support programs tailored to the specific needs of parents caring for a chronically ill child.

It should also be noted that the vast majority of children were in good health, with $85 \%$ of children demonstrating no or only mild impairment of lung function, yet levels of both anxious and depressive symptoms were clinically elevated for a large number of parents. It is possible that despite the dramatic increase in life span for those diagnosed with $\mathrm{CF}$, recently projected as 37.4 years (CF Foundation Registry, 2008), it appears that management of the disease takes a toll on parent caregivers. Future longitudinal studies should focus on the course of the child's disease and its effects on parental functioning. It is possible that as the child's condition worsens, symptoms of depression in parent caregivers may increase further and require referral to mental health specialists. The comparison of those families with a sick child $(\mathrm{N}=17)$ to the rest of the sample points in this direction. No significant group differences were found, however, this is likely to be an effect of the small sample size, as the numerical differences in the scores clearly indicate higher levels of depressive (and anxious) symptoms in the group with acute medical conditions.

\section{Life satisfaction}

Results on Life Satisfaction supported our hypothesis and converged with previous studies focusing on pediatric cancer patients $\frac{22.23}{2-z}$ with parents reporting less Life Satisfaction compared to the community sample. In the General Life Satisfaction module, the worst life satisfaction was reported in the domains of Leisure Activities, Job Situation and

Deleted: In interpreting these results, it should be noted that we applied the international cut-off score of 16 , even though an adjusted cut-off score of 23 has been recommended for German

samples. ${ }^{27}$ Applying this adjusted national
custer cut-off score, results of the parent sample were comparable to those found in the control group and no significant group differences emerged. Thus, our study methodology using the broadly applied international cut-off score of 16 might have led to an overestimation of symptoms of depression in the German parent caregiver sample. The different thresholds for cut-points in this screening measure needs further study and should be kept in mind when conducting crosscultural analyses of the international data set. II

Formatted: Superscript Deleted: ${ }^{16,17}$ 
Partnership/Sexuality. When interpreting these results, note that most of the respondents were mothers, who typically serve as the primary caregivers for their children and thus, have less

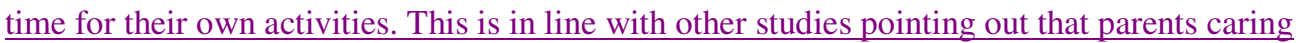
for a child with CF have less time as a couple to engage in social and recreational activities 3,47,48. Interestingly, parents reported better satisfaction with their family life compared to the community sample. This finding also fits with prior literature on family adaptation to

Deleted: When interpreting these results, note that most of the respondents were mothers, who typically serve as the primary caregivers for their children and thus, have less time for their own activities $\left(\right.$ see $\mathrm{also}^{3}$ )

chronic illness yielded similar results for parental quality of life, $\frac{21}{2}$ concluding that coping

with a child's chronic illness may strengthen family cohesion and decrease conflict, as parents

utilize the emotional support of other family members in their adaptation process. Further,

Health-Related Life Satisfaction in this parent sample was impaired in most of the life

domains reported. This may be explained by the burden of everyday management of the

disease, which results in excessive demands on parents (e.g., establishing good relationships with the $\mathrm{CF}$ healthcare team and integrating $\mathrm{CF}$ treatments into daily routines ${ }^{14}$ ) and

increased fatigue. As expected, anxious and depressive symptoms were negatively correlated with General and Health-related Life Satisfaction and with higher levels of symptom severity,

a finding that converges with others on quality of life in patients with CF and their families. $\frac{49}{z}$

\section{$\underline{\text { Study limitations }}$}

The strengths of this study include its multi-center design, large sample size and use of standardized screening measures. However, the study had also several limitations. First, we used data from comparison groups that were collected in previous studies. However, although we did not collect these data in a parallel manner, we successfully matched the community samples for age and gender. It is of course an interesting question whether or not parents caring for a child with CF should be compared to general population controls, given the very 
special circumstances and challenges of living with a chronically ill child which limit the comparability of these two groups. However, comparing parents of children with $\mathrm{CF}$ to a community sample seems to be a reasonable way to estimate the additional psychological distress of caring for a child with $\mathrm{CF}$ as opposed to "normal" levels of anxious and/or depressive symptoms. Unfortunately we have no information about the percentage of parents in the comparative populations. Thus, a biasing effect of being a parent could not be ruled out. Second, two widely used screening measures were employed to assess the prevalence of anxious and depressive symptoms, but these screening results were not further validated with a structured, clinical interview. Hence, it is important to note that the elevated rates of above cut-off screening results should not be mixed up with respective diagnoses of anxiety and/or depressive disorders but rather indicate that a more rigorous clinical assessment is warranted. Also, no multi-informant approach was used, but we only relied on parent self-report data. Additional selection biases may also have occurred in relation to which CF Centers in Germany decided to participate and which parents were recruited for the study. For example, in a sub-study in one clinical site of the German arm of the TIDES study ${ }^{50}$ the presence of a sample selection bias in terms of healthier persons being more likely to take part was shown. This allows for the suggestion, that the present results are rather underestimating the presence of symptoms of anxiety and/or depression requiring further clinical evaluation. Unfortunately, for practical reasons, we could not gather information on non-participants, which limits the generalizability of our results. However, the fact that we were able to recruit a large number of parents is supposed to counteract this threat to external validity,

The cross-sectional design of our study precluded the monitoring of how parental symptoms of anxiety, depression and life satisfaction affected long-term health outcomes. Future studies should investigate how changes in the child's health (e.g., acute exacerbations, new diagnosis of CF-related diabetes) affect parents' reports of psychological symptoms and 
quality of life. Thus, more complex, longitudinal studies are needed to examine the bidirectional nature of these relationships.

$\underline{\text { Conclusions }}$

These results provided evidence for the importance of measuring psychological symptoms and quality of life in parents caring for children with CF. Even though a huge part of the parents was doing fairly well overall, a significant proportion of caregivers was $\underline{\text { reporting borderline and clinical elevations of anxious and/or depressive symptoms. }}$

Therefore, systematic screening during routine care, followed by a more thorough clinical examination and the provision of psychosocial support and counselling if necessary may

\section{Acknowledgments}

The authors would like to thank all study centres and all patients and parent caregivers who participated in the current study for generously giving of their time and support. We also thank Paul Wenzlaff from the ZQM Hannover for his assistance with the analyses based on the registry data.

\section{Funding}

This study was supported by a financial grant from Mukoviszidose Institut $\mathrm{gGmbH}$, Bonn, the research and development arm of the German Cystic Fibrosis Association Mukoviszidose e.V. 
1. Barlow JH, Ellard DR. The psychosocial well-being of children with chronic disease, their parents and siblings: an overview of the research evidence base. Child Care Health Dev 2006;32:19-31.II

2. Kazak AE, Cant MC, Jensen MM, McSherry M, Rourke MT, Hwang WT, Alderfer MA, Beele D, Simms S, Lange BJ. Identifying psychosocial risk indicative of subsequent resource utilization in families of newly diagnosed pediatric oncology patients. J Clin Oncol 2003;21:3220-3225.II

3. Quittner AL, Espelage D, Opipari L, Carter B, Eid N, Eigen H. Role strain in couples with and without a child with chronic illness: Association with marital satisfaction, intimacy, and daily mood. Health Psychol 1998;17:112-124.II 4. Stern M, Sens B, Wiedemann B, Busse O, Damm G, Wenzlaff P.

Qualitätssicherung Mukoviszidose Überblick über den Gesundheitszustand der Patienten in Deutschland 2005. Berlin: Medizinisch Wissenschaftliche Verlagsgesellschaft; 2007.II

5. Barker DH, Quittner AL. A biopsychosocial model of CF: Social and emotional functioning, adherence and quality of life. In: Allen J, Panitch H, Rubenstein R, editors. Lung Biology in Health and Disease Series: Cystic Fibrosis. New York: Informa Healthcare; 2010.II

6. Modi AC, Marciel KK, Slater SK, Drotar D, Quittner AL. The influence of parental supervision on medical adherence in adolescents with cystic fibrosis: developmental shifts from pre to late adolescence. Child Health Care 2008;37:78-92.II

7. Patterson JM, Budd J, Goetz D, Warwick WJ. Family Correlates of a 10Year Pulmonary Health Trend in Cystic Fibrosis. Pediatrics 1993;91:383-389.II

. 8. Patterson JM, McCubbin HI, Warwick W. The impact of family functioning on health changes in children with cystic fibrosis. Soc Sci Med 1990;31:159-164. If

9. Ievers CE, Drotar D. Family and Parental Functioning in Cystic Fibrosis. J Dev Behav Pediatr 1996;17:48-55.II

10. Quittner AL, Barker DH, Marciel KK, Grimley ME. Cystic fibrosis: a model for drug discovery and patient care. In: Roberts MC, Steele RG, editors. Handbook of Pediatric Psychology. New York: Guilford Press; 2009. p 271-86.IL 11. Quittner AL, Barker DH, Snell C, Grimley ME, Marciel K, Cruz I. Prevalence and impact of depression in cystic fibrosis. Curr Opin PulmMed 2008;14:582-588. भा

12. Yilmaz O, Sogut A, Gulle S, Can D, Ertan P, Yuksel H. Sleep quality and depression-anxiety in mothers of children with two chronic respiratory diseases: Asthma and cystic fibrosis. J Cyst Fibros 2008;7:495-500. II

13. Smith BA, Modi AC, Quittner AL, Wood L. Depressive symptoms in children with cystic fibrosis and $p$ 


\section{Figure Legends}

Fig.1: Frequency of elevated scores on the HADS Anxiety Scale (ANX, normal: 0-7. borderline: $8-10$, abnormal: $\geq 11$ ) and the CES-D (DEPR, normal: 0-15, borderline/international cut-off: $16-23$, abnormal/German cut-off: $\geq 24)$ in the parent $\underline{\text { sample (parents) and in the general population sample (gen.pop.) }}$

Deleted: Comparison of $\mathrm{FLZ}^{\mathrm{M}}$ Genera (a) and Health-related (b) Life Satisfaction scores in the parent and community sample, significant differences are marked with an asterix* $\mathbb{\|}$ $\left({ }^{*} \mathrm{p} \leq .05, * * \mathrm{p} \leq .01, * * * \mathrm{p} \leq .001\right)$

\section{$\underline{\text { References }}$}

1. Barlow JH, Ellard DR. The psychosocial well-being of children with chronic disease, Formatted: Space After: $12 \mathrm{pt}$ their parents and siblings: an overview of the research evidence base. Child: Care, Health and Development 2006;32:19-31.

2. Kazak AE, Cant MC, Jensen MM, McSherry M, Rourke MT, Hwang WT, Alderfer MA, Beele D, Simms S, Lange BJ. Identifying psychosocial risk indicative of subsequent resource utilization in families of newly diagnosed pediatric oncology patients. J Clin Oncol 2003;21:3220-5.

3. Quittner AL, Espelage D, Opipari L, Carter B, Eid N, Eigen H. Role strain in couples with and without a child with chronic illness: Assoiciation with marital satisfaction, intimacy, and daily mood. Health Psychology 1998;17:112-24.

4. Stern M, Sens B, Wiedemann B, Busse O, Damm G, Wenzlaff P. Qualitätssicherung Mukoviszidose. Überblick über den Gesundheitszustand der Patienten in Deutschland 2005. Berlin: Medizinisch Wissenschaftliche Verlagsgesellschaft; 2007.

5. Barker DH, Quittner AL. A biopsychosocial model of CF: Social and emotional functioning, adherence and quality of life. In: Allen J, Panitch H, Rubenstein R, editors. Lung Biology in Health and Disease Series: Cystic Fibrosis. New York: Informa Healthcare; 2010.

6. Rapoff MA. Adherence to pediatric medical regimens. New York: Kluwer Academic/Plenum Publishers; 1999.

7. Modi AC, Lim CS, Yu N, Geller D, Wagner MH, Quittner AL. A multi-method assessment of treatment adherence for children with cystic fibrosis. Journal of Cystic Fibrosis 2006;5:177-85.

8. Quittner AL, Drotar D, Ievers-Landis CE, Slocum N, Seidner D, Jacobsen J. Adherence to medical treatments in children with cystic fibrosis: The development and evaluation of family-based interventions. In: Drotar D, editor. Promoting adherence to medical 
$\underline{\text { treatments in childhood chronic illness: concepts, methods and interventions. Mahwah }}$ N.J.: Lawrence Earlbaum Associates; 2000.

9. Anthony H, Paxon S, Bines J, Phelan P. Psychosocial predictors of adherence of nutritional recommendations and growth outcomes in children with cystic fibrosis. J psychosom Res 1999;47:623-34.

10. Modi AC, Marciel KK, Slater SK, Drotar D, Quittner AL. The influence of parental supervision on medical adherence in adolescents with cystic fibrosis: developmental shifts from pre to late adolescence. Children's Health Care 2008;37:78-92.

11. Patterson JM, Budd J, Goetz D, Warwick WJ. Family Correlates of a 10-Year Pulmonary Health Trend in Cystic Fibrosis. Pediatrics 1993;91 (2):383-9.

12. Patterson JM, McCubbin HI, Warwick W. The impact of family functioning on health changes in children with cystic fibrosis. Social Science and Medicine 1990;31 (2):15964.

13. Ievers CE, Drotar D. Family and Parental Functioning in Cystic Fibrosis. Journal of Developmental \& Behavioral Pediatrics 1996;17 (1):48-55.

14. Quittner AL, Barker DH, Marciel KK, Grimley ME. Cystic fibrosis: a model for drug discovery and patient care. In: Roberts MC, Steele RG, editors. Handbook of Pediatric Psychology. New York: Guilford Press; 2009. p 271-86.

15. Quittner AL, Barker DH, Snell C, Grimley ME, Marciel K, Cruz I. Prevalence and impact of depression in cystic fibrosis. Current Opinion in Pulmonary Medicine 2008;14:582-8.

16. Yilmaz O, Sogut A, Gulle S, Can D, Ertan P, Yuksel H. Sleep quality and depressionanxiety in mothers of children with two chronic respiratory diseases: Asthma and cystic fibrosis. Journal of Cystic Fibrosis 2008;7:495-500.

17. Driscoll KA, Montag-Leifling K, Acton JD, Modi AC. Relations Between Depressive and Anxious Symptoms and Quality of Life in Caregivers of Children With Cystic Fibrosis. Pediatric Pulmonology 2009;44:784-92.

18. Quittner, A. L., Barker, D. H., Geller, D., Butt, S., and Gondor, M. Effects of maternal depression on electronically monitored enzyme adherence and changes in weight for children with CF. [abstract]. In: Anonymous. 2007. p S77.

19. Smith BA, Modi AC, Quittner AL, Wood L. Depressive symptoms in children with cystic fibrosis and parents and its effects on adherence to airway clearance. Pediatric Pulmonology 2010. Forthcoming.

20. Lawoko S, Soares JJF. Quality of life among parents of children with congenital heart disease, parents of children with other diseases and parents of healthy children. Quality of Life Research 2003;12:655-66.

21. Goldbeck L. The impact of newly diagnosed chronic paediatric conditions on parental quality of life. Qual Life Res 2006 Sep;15(7):1121-31. 
22. Hatzmann J, Heymans HS, Carbonell A, van Praag BM, Grootenhuis MA. Hidden consequences of success in pediatrics: parental health-related quality of life--results from the Care Project. Pediatrics 2008;122.

23. Klassen AF, Klaassen R, Dix D, Pritchard S, Yanofsky R, O'Donnell M, Scott A, Sung L. Impact of caring for a child with cancer on parents' health-related quality of life. $\mathrm{J}$ Clin Oncol 2008;26:5884-9.

24. Goldbeck L, Besier T, Hinz A, Singer S, Quittner AL, and the TIDES study group. Prevalence of anxious and depressive symptoms in German patients with cystic fibrosis. Chest 2010;138:929-36.

25. Henrich G, Herschbach P. Questions on Life Satisfaction (FLZ ${ }^{\mathrm{M}}$ ) - A Short Questionnaire for Assessing Subjective Quality of Life. European Journal of Psychological Assessment 2000;16:150-9.

26. Zigmond AS, Snaith RP. The hospital anxiety and depression scale. Acta psychiatr scand 1983;67:361-70.

27. Herrmann C. International experiences with the hospital anxiety and depression scale - a review of validation data and clinical results. J psychosom Res 1997;42:17-41.

28. Bjelland I, Dahl AA, Haug TT, Neckelmann D. The validity of the Hospital Anxiety and Depression Scale. An updated literature review. J Psychosom Res 2002 Feb;52:69-77.

29. Herrmann-Lingen C, Buss U, Snaith RP. HADS-D Hospital Anxiety and Depression Scale - Deutsche Version. 2. Auflage ed. Bern: Huber; 2005.

30. Radloff LS. The CES-D scale: A self report depression scale for research in the general population. Applied Psychological Measurement 1977;1:385-401.

31. Hautzinger M, Bailer M. Allgemeine Depressionsskala. 1. Auflage ed. Göttingen: Hogrefe; 1993.

32. Herschbach P, Henrich G, Strasburger CJ, Feldmeier H, Marin F, Attanasio AM, Blum WF. Development and psychometric properties of a disease-specific quality of life questionnaire for adult patients with growth hormone deficiency. European Journal of Endocrinology 2001;145:255-65.

33. Goldbeck L, Schmitz TG. Comparison of three generic questionnaires measuring quality of life in adolescents and adults with cystic fibrosis: The 36-item short form health survey, the quality of life profile for chronic diseases, and the questions on life satisfaction. Quality of Life Research 2001;10 (1):23-36.

34. Goldbeck L, Zerrer S, Schmitz TG. Monitoring quality of life in outpatients with cystic fibrosis: feasibility and longitudinal results. J Cyst Fibros 2007 May;6(3):171-8.

35. Hinz A, Schwarz R. Angst und Depression in der Allgemeinbevölkerung. Psychotherapie Psychosomatik und medizinische Psychologie 2001;51:193-200. 
36. Henrich G, Herschbach P. FLZ - Fragen zur Lebenszufriedenheit Module Version für Erwachsene. Kurzbeschreibung und Vergleichsdaten. München: Klinik und Poliklinik für Psychosomatische Medizin, Psychotherapie und Medizinische Psychologie.; 2006.

37. Bortz J, Döring N. Forschungsmethoden und Evaluation für Human- und Sozialwissenschaftler. 4.Auflage ed. Heidelberg: Springer-Verlag; 2006.

38. Thoren CT, Petermann F. Reviewing asthma and anxiety. Respiratory Medicine 2000;94:409-15.

39. Brown ES, Gan V, Jeffress J, Mullen-Gingrich K, Khan DA, Wood BL, Miller BD, Gruchalla R, Rush AJ. Psychiatric Symptomatology and Disorders in Caregivers of Children with Asthma. Pediatrics 2006;118:e1715-e1720.

40. White T, Miller J, Smith GL, McMahon WM. Adherence and psychopathology in children and adolescents with cystic fibrosis. European child and adolescent psychiatry 2009;18:96-104.

41. Ullrich G, Wiedau-Görs S, Steinkamp G, Bartig HJ, Schulz W, Freihorst J. Parental fears of Pseudomonas infection and measures to prevent its acquisition. Journal of Cystic Fibrosis 2002;1:122-30.

42. Smith BA, Shuchman M. Problem of nonadherence in chronically ill adolescents: strategies for assessment and intervention. Current Opinion in Pediatrics 2005; 17:613-8.

43. Kendler KS, Davis CG, Kessler RC. The familial aggregation of common psychiatric and substance use disorders in the National Comorbidity survey: A family history study. British Journal of Psychiatry 1997;170:541-8.

44. Lieb R, Isensee B, Höfler M, Pfister H, Wittchen H-U. Parental Major Depression and the Risk of Depression and Other Mental Disorders in Offspring. Archives of General Psychiatry 2002;59:365-74.

45. Quittner AL, Slater S. Parenting stress, depression, and caregiving for young children with cystic fibrosis. Pediatric Pulmonology 2005;28:180-1.

46. Glasscoe C, Lancaster GA, Smyth RL, Hill J. Parental depression following the early diagnosis of cystic fibrosis: a matched, prospective study. J Pediatr 2007;150:185-91.

47. Quittner AL, Opipari LC, Regoli MJ, Jacobsen J, Eigen H. The Impact of Caregiving and Role Strain on Family Life: Comparisons between Mothers of Children with Cystic Fibrosis and Matched Controls. Rehabilitation Psychology 1992;37 (4):275-90.

48. Modi AC, Quittner AL. Utilizing computerized phone diary procedures to assess health behaviors in family and social contexts. Children's Health Care 2006;35:29-45.

49. Staab D, Wenninger K, Gebert N, Rupprath K, Bisson S, Trettin M, Paul KD, Keller KM, Wahn U. Quality of life in patients with cystic fibrosis and their parents: what is important besides disease severity? Thorax 1998;53:727-31.

50. Ullrich G, Wünderich R, Ammon M, Ballmann M, Bartig HJ. Extending the TIDES-CF Study to a health services research approach. In: Ullrich G, editor. Psychology in 
Medical Settings: Lung Transplantation and Cystic Fibrosis. Norderstedt: Books-ondemand; 2010. p 107-30.

$$
\begin{aligned}
& \text { Formatted: Indent: Before: } 0 \mathrm{pt} \text {, } \\
& \text { Hanging: } 27 \mathrm{pt} \text {, Line spacing: } \\
& \text { single, Tabs: } 18 \mathrm{pt} \text {, Right }+27 \mathrm{pt} \text {, } \\
& \text { Left + Not at } 36 \mathrm{pt}
\end{aligned}
$$




\section{Subjects}

\section{Parents of children and adolescents with CF}

A total of 650 parent caregivers (75.5\% mothers) of 564 minors with $\mathrm{CF}$ (0-17 years, $M=9.5, S D=4.6 ; 54.9 \%$ male) were consecutively recruited for the study during a routine clinic visit at their CF center. Participating patients were compared to those not participating in this study, but whose data are included in the German CF Registry. These data included socio-demographic (e.g., age, gender, education, living situation) and medical information (e.g., height, weight, $\mathrm{FEV}_{1} \%$ ). Fewer parents with children under the age of 6 years $(\mathrm{p}<.001)$ participated in this study than were represented in the Registry, and thus there were a few differences on age-correlated indicators (lower height and weight in the study sample, as expected for this age group). No other group differences were found, indicating that this sample was representative of the school-age and adolescent CF cohort in Germany.

In 478 cases, data were obtained from only one parent ( 73 fathers, 405 mothers), whereas we received two data sets (one from father, one from mother) for the remaining 86 children. Children's lung function, measured as $\mathrm{FEV}_{1} \%$ predicted, ranged from $15.7 \%$ to $138.7 \%(\mathrm{M}=89.8 \%, \mathrm{SD}=21.1)$, with $83.2 \%$ of the children falling in the normal to mild range of disease severity $\left(\mathrm{FEV}_{1} \% \geq 70\right)$ and only $2.5 \%$ falling in the severely impaired range $\left(\mathrm{FEV}_{1} \% \leq 40\right)$. Table 1 shows the characteristics of the parent sample, separately for mothers and fathers.

Insert Table 1 about here Normative data from the German general population 
To allow for group comparisons, we used the most recent instrument-specific data from normative reference samples. For the screening of anxiety, we used data from a German survey study. ${ }^{20}$ The general population sample was selected based on 216 sample points in Germany using the random-route-technique (random selection of street, house, flat and target subject in the household). This sample, with a response rate of $68 \%$, can be assumed to be representative of the adult German population living in private households. Individuals from foreign countries were not included in the sample because of problems with command of the German language. The original sample, with complete data consisted of 2037 people aged 14-92 years, with a mean age of $49.2(\mathrm{SD}=17.3)$. These respondents were matched for age and gender with our parent sample, leading to a sample size of 614 (22-60 years, $M=40.0$ years, $S D=7.2,76.4 \%$ female).

To analyse the data on depression we used comparative data from a representative population sample in cooperation with the German study group mentioned above ( $N=2005$, 14-91 years, $M=48.0, S D=18.3$ ). Matching for age and gender led to a sample size of 620 people aged 21-60 years ( $M=40.0$ years, $S D=7.3,76.6 \%$ female).

The life satisfaction data, measured with the Questions on Life Satisfaction $\left(\mathrm{FLZ}^{\mathrm{M}}\right)$, were also compared to community samples. For the general life satisfaction module, data came from a large community sample $(N=5036,14-92$ years, $M=48.4$, $S D=18.0,53.7 \%$ female). Comparison data for the health-related life satisfaction module came from the $\mathrm{FLZ}^{\mathrm{M}}$ standardization study ${ }^{21}$ with 1338 German adults from the community (17-95 years, $M=46.9, S D=17.2,54.6 \%$ female). An analogous matching procedure was completed for both samples, selecting those participants with an agegender combination paralleling the parent caregiver sample. Their responses were 
weighted so that the age and gender distribution in the two community samples paralleled the distribution in the parent caregiver sample. The matching procedure resulted in a sample of 2718 subjects for the general life satisfaction module and 768 subjects for the health-related life satisfaction module.

\section{References}

1. Barlow JH, Ellard DR. The psychosocial well-being of children with chronic disease, their parents and siblings: an overview of the research evidence base. Child Care Health Dev 2006;32:19-31.

2. Kazak AE, Cant MC, Jensen MM, McSherry M, Rourke MT, Hwang WT, Alderfer MA, Beele D, Simms S, Lange BJ. Identifying psychosocial risk indicative of subsequent resource utilization in families of newly diagnosed pediatric oncology patients. J Clin Oncol 2003;21:3220-3225.

3. Quittner AL, Espelage D, Opipari L, Carter B, Eid N, Eigen H. Role strain in couples with and without a child with chronic illness: Association with marital satisfaction, intimacy, and daily mood. Health Psychol 1998;17:112-124.

4. Stern M, Sens B, Wiedemann B, Busse O, Damm G, Wenzlaff P. Qualitätssicherung Mukoviszidose. Überblick über den Gesundheitszustand der Patienten in Deutschland 2005. Berlin: Medizinisch Wissenschaftliche Verlagsgesellschaft; 2007. 
5. Barker DH, Quittner AL. A biopsychosocial model of CF: Social and emotional functioning, adherence and quality of life. In: Allen J, Panitch H, Rubenstein R, editors. Lung Biology in Health and Disease Series: Cystic Fibrosis. New York: Informa Healthcare; 2010.

6. Modi AC, Marciel KK, Slater SK, Drotar D, Quittner AL. The influence of parental supervision on medical adherence in adolescents with cystic fibrosis: developmental shifts from pre to late adolescence. Child Health Care 2008;37:7892.

7. Patterson JM, Budd J, Goetz D, Warwick WJ. Family Correlates of a 10-Year Pulmonary Health Trend in Cystic Fibrosis. Pediatrics 1993;91:383-389.

8. Patterson JM, McCubbin HI, Warwick W. The impact of family functioning on health changes in children with cystic fibrosis. Soc Sci Med 1990;31:159-164.

9. Ievers CE, Drotar D. Family and Parental Functioning in Cystic Fibrosis. J Dev Behav Pediatr 1996;17:48-55.

10. Quittner AL, Barker DH, Marciel KK, Grimley ME. Cystic fibrosis: a model for drug discovery and patient care. In: Roberts MC, Steele RG, editors. Handbook of Pediatric Psychology. New York: Guilford Press; 2009. p 271-86.

11. Quittner AL, Barker DH, Snell C, Grimley ME, Marciel K, Cruz I. Prevalence and impact of depression in cystic fibrosis. Curr Opin PulmMed 2008;14:582588. 
12. Yilmaz O, Sogut A, Gulle S, Can D, Ertan P, Yuksel H. Sleep quality and depression-anxiety in mothers of children with two chronic respiratory diseases: Asthma and cystic fibrosis. J Cyst Fibros 2008;7:495-500.

13. Smith BA, Modi AC, Quittner AL, Wood L. Depressive symptoms in children with cystic fibrosis and parents and its effects on adherence to airway clearance. Pediatr Pulmonol 2010. Forthcoming.

14. Lawoko S, Soares JJF. Quality of life among parents of children with congenital heart disease, parents of children with other diseases and parents of healthy children. Qual Life Res 2003;12:655-666.

15. Goldbeck L. The impact of newly diagnosed chronic paediatric conditions on parental quality of life. Qual Life Res 2006 Sep;15:1121-1131.

16. Hatzmann J, Heymans HS, Carbonell A, van Praag BM, Grootenhuis MA. Hidden consequences of success in pediatrics: parental health-related quality of liferesults from the Care Project. Pediatrics 2008;122: e1030-e1038.

17. Klassen AF, Klaassen R, Dix D, Pritchard S, Yanofsky R, O'Donnell M, Scott A, Sung L. Impact of caring for a child with cancer on parents' health-related quality of life. J Clin Oncol 2008;26:5884-5889.

18. Goldbeck L, Besier T, Hinz A, Singer S, Quittner AL, and the TIDES study group. Prevalence of anxious and depressive Symptoms in German patients with Cystic Fibrosis. Chest 2010. Forthcoming. 
19. Henrich G, Herschbach P. Questions on Life Satisfaction $\left(F_{L Z}{ }^{\mathrm{M}}\right)$ - A Short Questionnaire for Assessing Subjective Quality of Life. Eur J Psychol Assess 2000;16:150-159.

20. Hinz A, Schwarz R. Angst und Depression in der Allgemeinbevölkerung. Psychother Psychosom Med Psychol 2001;51:193-200.

21. Henrich G, Herschbach P. FLZ ${ }^{M}$ - Fragen zur Lebenszufriedenheit ${ }^{\text {Module }}$. Version für Erwachsene. Kurzbeschreibung und Vergleichsdaten. München: Klinik und Poliklinik für Psychosomatische Medizin, Psychotherapie und Medizinische Psychologie; 2006.

22. Zigmond AS, Snaith RP. The hospital anxiety and depression scale. Acta psychiatr scand 1983;67:361-370.

23. Herrmann C. International experiences with the hospital anxiety and depression scale - a review of validation data and clinical results. J Psychosom Res $1997 ; 42: 17-41$.

24. Bjelland I, Dahl AA, Haug TT, Neckelmann D. The validity of the Hospital Anxiety and Depression Scale. An updated literature review. J Psychosom Res 2002;52:69-77.

25. Herrmann-Lingen C, Buss U, Snaith RP. HADS-D Hospital Anxiety and Depression Scale - Deutsche Version. $2^{\text {nd }}$ ed. Bern: Huber; 2005. 
26. Radloff LS. The CES-D scale: A self report depression scale for research in the general population. Appl Psychol Meas 1977;1:385-401.

27. Hautzinger M, Bailer M. Allgemeine Depressionsskala. $1^{\text {st }}$ ed. Göttingen: Hogrefe; 1993.

28. Herschbach P, Henrich G, Strasburger CJ, Feldmeier H, Marin F, Attanasio AM, Blum WF. Development and psychometric properties of a disease-specific quality of life questionnaire for adult patients with growth hormone deficiency. Eur $\mathbf{J}$ Endocrinol 2001;145:255-265.

29. Goldbeck L, Schmitz TG. Comparison of three generic questionnaires measuring quality of life in adolescents and adults with cystic fibrosis: The 36-item short form health survey, the quality of life profile for chronic diseases, and the questions on life satisfaction. Qual Life Res 2001;10:23-36.

30. Goldbeck L, Zerrer S, Schmitz TG. Monitoring quality of life in outpatients with cystic fibrosis: feasibility and longitudinal results. J Cyst Fibros 2007;6:171-178.

31. Bortz J, Döring N. Forschungsmethoden und Evaluation für Human- und Sozialwissenschaftler. $4^{\text {th }}$ ed. Heidelberg: Springer-Verlag; 2006.

32. Thoren CT, Petermann F. Reviewing asthma and anxiety. Respir Med 2000;94:409-415. 
33. Brown ES, Gan V, Jeffress J, Mullen-Gingrich K, Khan DA, Wood BL, Miller BD, Gruchalla R, Rush AJ. Psychiatric Symptomatology and Disorders in Caregivers of Children with Asthma. Pediatrics 2006;118:e1715-e1720.

34. White T, Miller J, Smith GL, McMahon WM. Adherence and psychopathology in children and adolescents with cystic fibrosis. Eur Child Adolesc Psychiatry 2009; 18:96-104.

35. Ullrich G, Wiedau-Görs S, Steinkamp G, Bartig HJ, Schulz W, Freihorst J. Parental fears of Pseudomonas infection and measures to prevent its acquisition. $\mathbf{J}$ Cyst Fibros 2002;1:122-130.

36. Smith BA, Shuchman M. Problem of nonadherence in chronically ill adolescents: strategies for assessment and intervention. Curr Opin Pediatr 2005;17:613-618.

37. Staab D, Wenninger K, Gebert N, Rupprath K, Bisson S, Trettin M, Paul KD, Keller KM, Wahn U. Quality of life in patients with cystic fibrosis and their parents: what is important besides disease severity? Thorax 1998;53:727-731. 


\section{Response to re-reviews}

Dear Dr. Chernick,

Many thanks for forwarding the reviewers' comments on the revised version of our manuscript. We are pleased to learn that our manuscript has been provisionally accepted for publication in Pediatric Pulmonology. Again, we would like to thank the reviewers for their valuable and helpful comments during the review process.

\section{\# reviewer 1:}

We apologize for not having updated the reference list in the marked version of the revision. However, the updated reference list including all references cited in the revised text was already attached to the "clean version" of the revision (R1clean). We have now also updated the reference list in the marked version of the revision (R2marked). No other changes have been made to the manuscript.

Best wishes,

Tanja Besier

Corresponding author 
Fig.1: Frequency of elevated scores on the HADS Anxiety Scale (ANX, normal: 0-7, borderline: 8-10, abnormal: $\geq 11$ ) and the CES-D (DEPR, normal: 0-15, borderline/international cut-off: 16-23.

abnormal/German cut-off: $\geq 24$ ) in the parent sample (parents) and in the general population sample (gen.pop.)

$254 \times 190 \mathrm{~mm}(96 \times 96 \mathrm{DPI})$

John Wiley \& Sons, Inc. 
Table 1: Study sample characteristics

\begin{tabular}{|c|c|c|}
\hline Characteristics & $\begin{array}{l}\text { Mothers } \\
\text { of minors } \\
\text { with CF } \\
(\mathrm{N}=491)\end{array}$ & $\begin{array}{r}\text { Fathers } \\
\text { of minors } \\
\text { with } \mathrm{CF} \\
(\mathrm{N}=159)\end{array}$ \\
\hline \multicolumn{3}{|l|}{ Age (in years) } \\
\hline range & $21-56$ & $26-64$ \\
\hline $\mathrm{M}(\mathrm{SD})$ & $39.3(6.1)$ & $41.4(6.4)$ \\
\hline \multicolumn{3}{|l|}{ Education (in \%) } \\
\hline no graduation & 1.2 & 1.3 \\
\hline secondary school (9-10 years) & 64.3 & 65.4 \\
\hline high school (12-13 years) & 16.1 & 7.7 \\
\hline university degree & 17.6 & 25.6 \\
\hline \multicolumn{3}{|l|}{ Job situation (in \%) } \\
\hline employed, full-time/shift-working & 11.2 & 91.3 \\
\hline employed, part-time & 47.4 & 4.6 \\
\hline occasionally working & 7.7 & 1.3 \\
\hline homemaker & 30.3 & - \\
\hline retired & 0.2 & 2.0 \\
\hline
\end{tabular}


Table 2: Comparison of general and health-related life satisfaction scores in the parent and community sample (t-tests for independent samples)

\begin{tabular}{|c|c|c|c|c|c|c|c|}
\hline Scale & Subscales & Group & $N$ & $M$ & $S D$ & $t$ & $p$ \\
\hline \multirow{9}{*}{$\begin{array}{l}\text { general life } \\
\text { satisfaction }\end{array}$} & friends & $\begin{array}{l}\text { parents } \\
\text { community }\end{array}$ & $\begin{array}{r}602 \\
2717\end{array}$ & $\begin{array}{l}8.64 \\
8.83\end{array}$ & $\begin{array}{l}6.26 \\
5.83\end{array}$ & -0.70 & .486 \\
\hline & $\begin{array}{l}\text { leisure } \\
\text { activities }\end{array}$ & $\begin{array}{l}\text { parents } \\
\text { community }\end{array}$ & $\begin{array}{r}599 \\
2714\end{array}$ & $\begin{array}{l}5.51 \\
6.84\end{array}$ & $\begin{array}{l}6.09 \\
5.74\end{array}$ & -5.04 & $<.001$ \\
\hline & health & $\begin{array}{l}\text { parents } \\
\text { community }\end{array}$ & $\begin{array}{r}594 \\
2715\end{array}$ & $\begin{array}{r}7.44 \\
10.54\end{array}$ & $\begin{array}{l}7.36 \\
6.61\end{array}$ & -9.49 & $<.001$ \\
\hline & money & $\begin{array}{l}\text { parents } \\
\text { community }\end{array}$ & $\begin{array}{r}587 \\
2713\end{array}$ & $\begin{array}{l}6.25 \\
5.97\end{array}$ & $\begin{array}{l}6.40 \\
7.24\end{array}$ & 0.91 & .365 \\
\hline & job situation & $\begin{array}{l}\text { parents } \\
\text { community }\end{array}$ & $\begin{array}{r}567 \\
2706\end{array}$ & $\begin{array}{l}5.98 \\
6.70\end{array}$ & $\begin{array}{l}6.41 \\
7.72\end{array}$ & -2.34 & .019 \\
\hline & living situation & $\begin{array}{l}\text { parents } \\
\text { community }\end{array}$ & $\begin{array}{r}596 \\
2717\end{array}$ & $\begin{array}{l}9.57 \\
9.37\end{array}$ & $\begin{array}{l}6.30 \\
6.51\end{array}$ & 0.69 & .490 \\
\hline & family & $\begin{array}{l}\text { parents } \\
\text { community }\end{array}$ & $\begin{array}{r}585 \\
2711\end{array}$ & $\begin{array}{l}12.20 \\
11.26\end{array}$ & $\begin{array}{l}6.95 \\
7.42\end{array}$ & 2.94 & .003 \\
\hline & $\begin{array}{l}\text { partnership/ } \\
\text { sexuality }\end{array}$ & $\begin{array}{l}\text { parents } \\
\text { community }\end{array}$ & $\begin{array}{r}552 \\
2710\end{array}$ & $\begin{array}{l}7.74 \\
9.57\end{array}$ & $\begin{array}{l}7.43 \\
7.89\end{array}$ & -5.01 & $<.001$ \\
\hline & total & $\begin{array}{l}\text { parents } \\
\text { community }\end{array}$ & $\begin{array}{r}588 \\
2717\end{array}$ & $\begin{array}{l}63.36 \\
69.09\end{array}$ & $\begin{array}{l}35.79 \\
38.20\end{array}$ & -3.33 & .001 \\
\hline $\begin{array}{c}\text { health- } \\
\text { related life }\end{array}$ & $\begin{array}{l}\text { physical } \\
\text { condition }\end{array}$ & $\begin{array}{l}\text { parents } \\
\text { community }\end{array}$ & 593 & $\begin{array}{l}6.76 \\
8.72\end{array}$ & $\begin{array}{l}6.39 \\
6.47\end{array}$ & -5.57 & $<.001$ \\
\hline satisfaction & ability to relax & parents & 592 & 5.43 & 6.56 & -4.86 & $<.001$ \\
\hline
\end{tabular}




\begin{tabular}{|c|c|c|c|c|c|c|}
\hline & community & 768 & 7.16 & 6.46 & & \\
\hline energy/zest for & parents & 587 & 7.55 & 7.26 & \multirow[b]{2}{*}{-4.44} & \multirow[b]{2}{*}{$<.001$} \\
\hline life & community & 768 & 9.22 & 6.31 & & \\
\hline \multirow[t]{2}{*}{ mobility } & parents & 589 & 10.78 & 6.35 & \multirow[b]{2}{*}{1.92} & \multirow[b]{2}{*}{.056} \\
\hline & community & 768 & 10.11 & 6.44 & & \\
\hline \multirow[t]{2}{*}{ vision/hearing } & parents & 589 & 11.93 & 6.48 & \multirow[b]{2}{*}{-0.77} & \multirow[b]{2}{*}{.444} \\
\hline & community & 767 & 12.21 & 6.69 & & \\
\hline freedom from & parents & 589 & 7.83 & 6.99 & \multirow[b]{2}{*}{-2.30} & \multirow[b]{2}{*}{.022} \\
\hline anxiety & community & 765 & 8.69 & 6.62 & & \\
\hline $\begin{array}{l}\text { freedom from } \\
\text { aches/pains }\end{array}$ & $\begin{array}{l}\text { parents } \\
\text { community }\end{array}$ & 589 & $\begin{array}{r}8.43 \\
10.15\end{array}$ & $\begin{array}{l}7.44 \\
6.75\end{array}$ & -4.38 & $<.001$ \\
\hline $\begin{array}{l}\text { independence } \\
\text { of help/care }\end{array}$ & $\begin{array}{l}\text { parents } \\
\text { community }\end{array}$ & $\begin{array}{l}586 \\
767\end{array}$ & 12.17 & $\begin{array}{l}6.89 \\
6.12\end{array}$ & -4.50 & $<.001$ \\
\hline total & $\begin{array}{l}\text { parents } \\
\text { community }\end{array}$ & $\begin{array}{r}591 \\
768\end{array}$ & $\begin{array}{l}70.72 \\
80.02\end{array}$ & $\begin{array}{l}40.08 \\
38.24\end{array}$ & -9.30 & $<.001$ \\
\hline
\end{tabular}


Table 3: Results of the two ANCOVAs for weighted Life Satisfaction scores as dependent factors and level of symptom severity on the HADS Anxiety scale (normalborderline-abnormal) and on the CES-D (normal-international cut-off 16-German cutoff 24) as independent factors, controlling for child age and lung function

\begin{tabular}{|c|c|c|c|c|c|c|}
\hline & & $N$ & $M(S D)$ & $F$ & $p$ & $\eta^{2}$ \\
\hline \multicolumn{7}{|c|}{ General Life Satisfaction } \\
\hline \multirow[t]{3}{*}{ HADS-Anxiety } & normal & 211 & $69.5(33.8)$ & & & \\
\hline & borderline & 75 & $54.9(33.8)$ & 14.133 & $<.001$ & .077 \\
\hline & abnormal & 58 & $43.5(36.7)$ & & & \\
\hline \multirow[t]{3}{*}{ CES-Depression } & normal & 232 & $70.6(31.8)$ & & & \\
\hline & cut-off 16 & 72 & $48.8(34.7)$ & 29.502 & $<.001$ & .147 \\
\hline & cut-off 24 & 43 & $32.4(37.3)$ & & & \\
\hline \multicolumn{7}{|c|}{ Health-related Life Satisfaction } \\
\hline \multirow[t]{3}{*}{ HADS-Anxiety } & normal & 239 & $83.9(36.7)$ & & & \\
\hline & borderline & 85 & $56.5(31.8)$ & 36.957 & $<.001$ & .162 \\
\hline & abnormal & 63 & $43.4(45.0)$ & & & \\
\hline \multirow[t]{3}{*}{ CES-Depression } & normal & 266 & $85.1(34.7)$ & & & \\
\hline & cut-off 16 & 79 & $46.6(33.4)$ & 62.779 & $<.001$ & .245 \\
\hline & cut-off 24 & 47 & $35.3(41.9)$ & & & \\
\hline
\end{tabular}

